\title{
Application of Genetic Algorithms to Optimization of Medium and Heavy Rotating Equipment Foundations
}

\author{
Nulu Reddeppa ${ }^{1, ~ *, ~ B o m m i r e d d y ~ J a y a r a m i ~ R e d d y ², ~ H a n c h a t e ~ S u d a r s a n a ~ R a o ~}{ }^{1}$ \\ ${ }^{1}$ Department of Civil Engineering, Jawaharlal Nehru Technological University, Anantapuramu, India \\ ${ }^{2}$ Directorate of IIIT, Rajiv Gandhi University of Knowledge Technologies, Ongole, India
}

Email address:

nreddeppa@gmail.com (N. Reddeppa)

${ }^{*}$ Corresponding author

\section{To cite this article:}

Nulu Reddeppa, Bommireddy Jayarami Reddy, Hanchate Sudarsana Rao. Application of Genetic Algorithms to Optimization of Medium and Heavy Rotating Equipment Foundations. American Journal of Civil Engineering. Vol. 9, No. 6, 2021, pp. 194-212.

doi: $10.11648 /$ j.ajce.20210906.13

Received: October 18, 2021; Accepted: November 8, 2021; Published: November 17, 2021

\begin{abstract}
Optimal structural design involves dealing with three main factors visibly cross-sectional properties of the members, topology and configuration and meeting the intended functional requirements. Most of the traditional optimization techniques are based on the mathematical programming techniques, which assume that the variables are continuous, but whereas the process of structural design is generally characterized by finite often large numbers of variables of discrete in nature. Genetic Algorithm is the technique which can be used efficiently for the design optimization of the structure with discrete variables. From the study on previous work done on GA's application in civil engineering, it has been noticed that application of GA's is not attempted in rotating machine foundations where there is scope for determining suitable optimum shape and member sizes to achieve a well-tuned foundation. Dynamic design of machine foundation involves broad criterion such as foundation natural frequency shall be away from the machine operating frequency and foundation displacement amplitudes shall be well within the specified allowable limits. The above criterion largely depends on design factors such as size of members, shape of the foundations, concrete grade and soil characters. Presently obtaining a best suitable solution meeting the frequency and amplitude criteria by varying above four design factors involves many manual trails. This involves lot of computer and human efforts to try various combinations to arrive at the solution. Considerable resources and time need to be spent on arriving a suitable solution. Yet the solution so arrived may not be an optimum solution. In this work, Genetic algorithms is applied for optimization of solution time and foundation volume for industrial medium and heavy rotating equipment foundations. Optimum solution is obtained with above variables by setting frequency as target criteria. The optimum solution obtained from Genetic Algorithms is further verified for its compliance to its intended functional parameters by means of finite element model study.
\end{abstract}

Keywords: Genetic Algorithm, Mill Foundation, Turbine Generator Foundation, Induced Draft Fan Foundation, Shape Optimization

\section{Introduction}

Solution to any General Structural Engineering problem consists of two phases. One is analysis and Design and the other is its implementation. Designer would like a structure to be light in weight and serve its intended purpose effectively. To achieve this, one will not look back to select complicated structural systems. This gives rise to problems of construction, increase in construction costs etc. When the time of implementation of the design arises, the construction team wishes a smaller number of member sizes with simple structural configurations. Also, the user wishes the structure to be stable without undergoing large deformations. So, a good design is the one which suits user's requirements, yet which is easy for the contractor and has minimum weight. 
A Structure having members with minimum crosssectional areas may be of minimum weight and may satisfy the stress limit but may not always satisfy the deflection condition. Higher the depth of the section, lower the deflection. So there exists a particular combination of areas for which the structure is stable, light and serviceable.

Further, the behavior of any structure depends on its topology and configuration. It is possible to arrive to a particular configuration and topology for which the weight of the structure is a minimum yet meeting the intended purposes.

From the afore mentioned statements, it is, clear that an optimal structural design includes three main factors. These are cross sectional properties of the members, topology and configuration. There is a need for a technique which can handle the above three features efficiently for the design optimization of the structure.

Normally, any Structural Engineering problem will have large number of solutions out of which some are feasible, and some are infeasible solutions. The designer's task now is to get the best solution out of these feasible solutions. The complete set of feasible solutions constitutes for feasible design space and the progress towards the optimal design will involve some kind of search within this space (combinatorial optimization). The searches are of two kinds. One is deterministic, the second is stochastic.

In the case of deterministic search, algorithm methods such as Steepest Gradient methods are employed (using the gradient concept), whereas in stochastic approach, random variables are introduced. Whether the search is deterministic or stochastic, it is possible to improve the reliability of the result, where reliability means nearness to optimum. To improve the reliability of the result in the search process, a transition rule is used in the algorithm. Essentially, algorithms vary according to the transition rule used to improve the result.

Most of these traditional optimization methods used in engineering design can be divided into two broad classes: Direct Search methods and Gradient Search methods. Direct Search methods are expensive and in most cases, they seem to work at simple unimodal functions. Gradient based methods require the knowledge of functions and constraints. Here, there is no guarantee of obtaining the global minimum, because usually these algorithms terminate when the gradient of the objective function is very close to zero, which may happen both in the case of global and local extremum. The calculation of the gradient is itself not a simple task. In most of the Structural Engineering problems, the variables in the objective functions and variables in the constraint equation are different. In such cases, obtaining the gradient of the constraints and measuring it in terms of the variables of the objective function becomes a tough task.

Some gradient based methods require computation of the Hessian Matrix, the numerical computation of which is not accurate and furthermore turns out to be expensive. Moreover, if some of the design variables are integers, numerical gradient computation becomes an uphill task.

As these methods are based on the mathematical programming techniques, which assume that the variables are continuous, but whereas the process of structural design is generally characterized by finite often large numbers of variables of discrete nature. Considering steel structures, the Universal Steel Sections available to the designer are discrete in dimensions and properties. Thus, a solution obtained by using mathematical programming techniques may not be feasible always.

In the case of optimization of shape or configuration, the process "is highly difficult because they have to handle different types of design variables. Many review papers on design optimization conclude with an emphasis on the need for methodology to solve configuration and topology optimization problems.

The above discussion suggests that in order to solve complex, multimodal, discrete or discontinuous problems, one needs better method that is robust search technique that can be applied to variety of problems with ease. Most of the traditional methods are not robust because each of them is specialized to solve a particular class of problems. The aim of this study is not to prove that the traditional algorithms are useless, in fact they have been widely used in many engineering optimization problems. The present study is only to stress the need for a robust technique which can be adopted for a variety of problems involving discrete variables with ease [1].

In this work a simple robust technique called the Genetic Algorithm (GA) [2-6] is explained and is used for optimization of solution time and foundation volume for industrial machine foundations. It is also used to optimize the configuration of machine foundations. Some of the examples from literature are discussed in this report for demonstrating genetic algorithms applications in civil engineering field [7].

\section{Genetic Algorithms in Brief}

Genetic Algorithms (GA) were developed in the midsixties by Prof. John Holland of Michigan University. Later many researchers contributed to its development. But the main success of GA today is due to the work of Prof. Davide E. Goldberg, University of Alabama [2].

'Genetic Algorithms come under the Stochastic Search method. They are computationally simple, but powerful in their search and there is always a room for improvement. They work on the principle of natural selection and survival of the fittest. An initial "Population" is generated by random selection of the individual bits in a binary string of given length. The strings (individuals) represent, 'directly or indirectly, the design variables in the objective function. Each individual population represents one solution for the problem of course at the beginning it may be infeasible. The fitness of each individual is then evaluated and assessed against the objective function. The 
individuals in the best families are given favorable weightings in a selection process. Then the parents are chosen randomly and mated by a cross over process. It is useful also to introduce an element of mutation in which some bits are switched ( 0 to 1 or 1 to 0 ) to encourage the development of new genetic material.

After each cycle of selection, cross over and possibly mutation, the fitness of each family is again assessed by converting the binary strings to decimal digits (decoding) and evaluating the objective function. The cycle then continues for the next generation.

The process is terminated when desired convergence is achieved or when the specified maximum number of generations is reached.

\section{Objective of Present Work}

GA is simple and powerful tool for the modern designer. In this investigation, GA's are used for the discrete design optimization of machine foundations. From the study on previous work done on GA's application in civil engineering, it has been noticed that application of GA's are never tried in the area of machine foundations where there is scope for determining suitable shape and member sizes to achieve a well-tuned foundation. Dynamic design of machine foundation involves following broad criterions.

1. Foundation natural frequency shall be away from the machine operating frequency.

2. Foundation displacement amplitudes shall be well within the specified allowable limits.

The above two criteria largely depend on following factors.

1. Size of members.

2. Shape of the foundations.

3. Concrete grade.

4. Soil characters.

Presently obtaining a best suitable solution meeting the frequency and amplitude criteria by varying above four factors involves many manual trails. This involves significant computer and human efforts to try various combinations to arrive at the solution. Considerable resources and time need to be spent on arriving a suitable solution. In this work, Genetic algorithms are applied to obtain the suitable solution with above variables setting frequency as target criteria.

The present area of work would be on application of GA's to Machine Foundations to arrive well-tuned foundations with respect to frequencies and displacement amplitudes with optimum sizes and configuration.

Machine foundations are categorized as following three type of foundations based on the machine speed and foundation geometry.

1. Rectangular concrete block foundation provided as the foundation for low frequency rotating equipment such as coal mills. The frequency of the equipment ranges from 30 to $40 \mathrm{rpm}$ [8].
2. Framed type foundation provided as the foundation for high frequency machine foundations such as turbo generator foundations. The frequency of the turbo generator falls in the range of $3000 \mathrm{rpm}$ [8].

3. Semi framed foundation provided as the foundation for medium frequency machine foundations such as fans. The frequency of fans falls in the range of $750 \mathrm{rpm}$ to $1500 \mathrm{rpm}[8]$.

Application of genetic algorithms is studied for the above three types of foundations.

Low frequency machines:

Scope of genetic algorithm application for low frequency machine such as coal mill foundation was studied and after detailed design it is understood that its sizing is governed by the adjacent bunker building foundation levels and equipment base frame configuration. The plan size adopted was the least size required to accommodate the equipment base. The foundation depth was governed by pile cut off level or foundation founding level of the adjacent bunker building column foundations. With these sizing requirements, foundation natural frequency was found to be close to motor operating frequency. This was managed by changing concrete grade without changing any other geometry and the foundation fundamental natural frequencies could be kept away from both mill and motor operating frequencies with the required margins.

It was observed that, frequency separation criteria was achieved by only changing concrete grade alone. This has resulted in reducing number of variables to be dealt to only material properties.

Principles of GA will have least role to play when number of variables are minimum. Under such circumstances the problem can be handled using manual trails with ease. Hence it is established that, the application of Genetic Algorithm for coal mill foundation will not yield any appreciable results.

High frequency machines:

Scope of genetic algorithm application for high frequency machines such as turbine generator foundation was also studied. Turbine generator foundation is a framed type foundation and after detailed design it was understood that, its sizing is governed by the static design requirements rather than dynamic design conditions [9].

Foundation member sizes are not governed by frequency separation criteria rather they are governed by codes norms and static design requirements. The top deck plan size adopted was the least size required to accommodate the equipment base. The raft plan size adopted was the least size required to accommodate the columns. The top deck thickness, raft thickness and column sizes are governed by stipulations of relevant standards and static design requirements. The member sizes complying above conditions are satisfying the dynamic frequency criteria. Some cases only displacement amplitudes and few local modes are governed by the concrete grade. This is managed by changing the concrete grades. 
It is noted that, the desired frequency separation criteria were achieved with least possible foundation sizes that are required to comply static design requirements, relevant standards with minimum trails. This has resulted in reducing variables to be dealt to only material properties. Hence there is a little scope for the foundation design optimization under such situations satisfying the dynamic criteria by keeping only material grade as variables.

Principles of GA will have least role to play when number of variables are minimum. Under such circumstances the problems are handled using manual trails with ease. Hence it is established that, the application of Genetic Algorithm's for turbine generator foundation do not serve intended purpose.

\section{Genetic Algorithms to Semi Framed (Fan) Foundations}

\subsection{Induced Draft Fan Foundation}

Semi-framed foundation is generally adopted for fan foundations $[10,11]$ in thermal power plants. The choice of the foundation type is decided by the functional position, elevation of the fan and its geometric supporting arrangement. Induced Draft Fan (ID Fan) of 800MW capacity thermal power plant is chosen for the study purpose.

Induced draft fan is used in thermal power plants for creating required draft in coal fired flue gas to let it into the atmosphere through tall chimney. The fan normally runs at a speed of 750 revolutions per minute (RPM). The typical fan is shown in following figure (Figure 1).

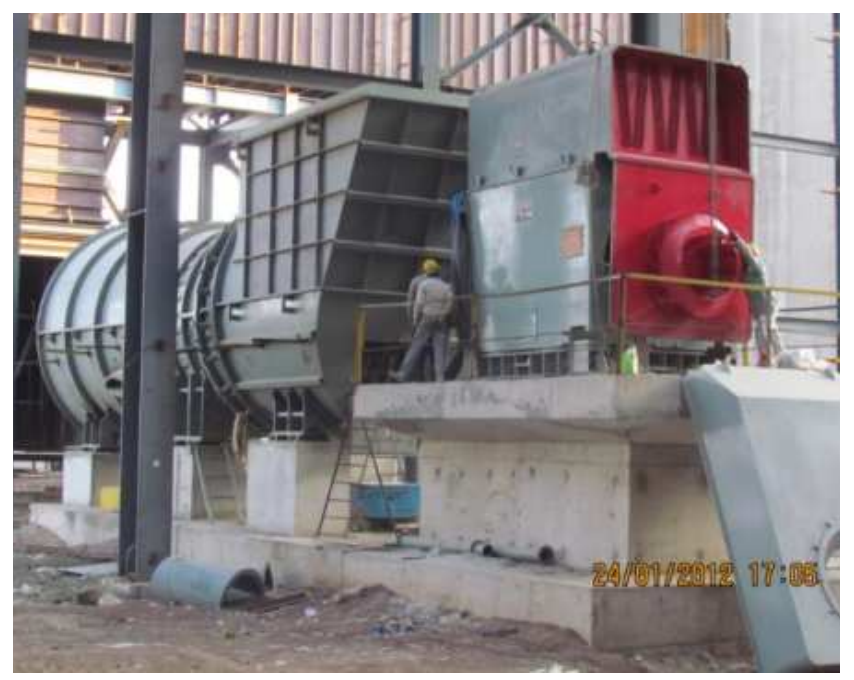

Figure 1. Typical ID Fan resting on Foundation.

ID fan foundation is one of the critical foundations in thermal power plants. Design of foundation for ID fan is done considering both statics and dynamic aspects. Any abnormal fan vibrations due to improper design may lead to operational problems, shutdowns, and curtailed operations of power plants. Hence safe and optimum design of foundation for this critical equipment is an important aspect in power plants.

Development of advanced analysis and design tools such as ANSYS, Nastran etc.., helped in understand the behavior of these equipment foundations under various loading conditions. Also, it helped in adapting framed type foundation in place of conventional block type foundations.

\subsection{Design of ID Fan Foundation}

Figure 1 to Figure 6 shows the general arrangement of an ID fan for $800 \mathrm{MW}$ thermal power plant. Design of machine foundation consists of following sequence of design activities.

1. Dynamic analysis is performed for assumed member sizes, material parameters and shape of the foundation.

2. Foundation natural frequencies are verified with machine operating frequency to satisfy following frequency separation criteria.

3. Foundation natural frequencies shall be $20 \%$ away from the machine operating frequency to avoid resonance.

4. Further static analysis and reinforcement design is carried out after satisfying above natural frequency separation criteria.

Dynamic analysis is performed for fan foundation using ANSYS software Finite Element Method (FEM) approach $[10,11]$. The above design activities largely influenced by following factors.

1. Size of members.

2. Shape of the foundations.

3. Concrete grade.

4. Soil characters.

Presently obtaining a best suitable and optimum solution meeting the frequency and amplitude criteria by combination of above four factors involves many trails. Member sizes, material parameters and foundation shape are assumed based on experience and several FEM models were developed, and dynamic analysis was performed until frequency and amplitude criteria is satisfied. This requires lot of computer and human efforts to try various combinations to arrive at the solution using software's like ANSYS etc. Considerable resources and time must be spent on arriving a suitable and optimum solution. Several possible solutions are obtained satisfying the frequency and amplitude criteria and optimum solution is picked from this pool of possible solutions. The details of such solution are illustrated in the following section.

\subsection{ID FAN Foundation Design Adopted Based on Manual Trails}

\subsubsection{Foundation Data}

The foundation geometry is considered as per equipment supplier's input data. 


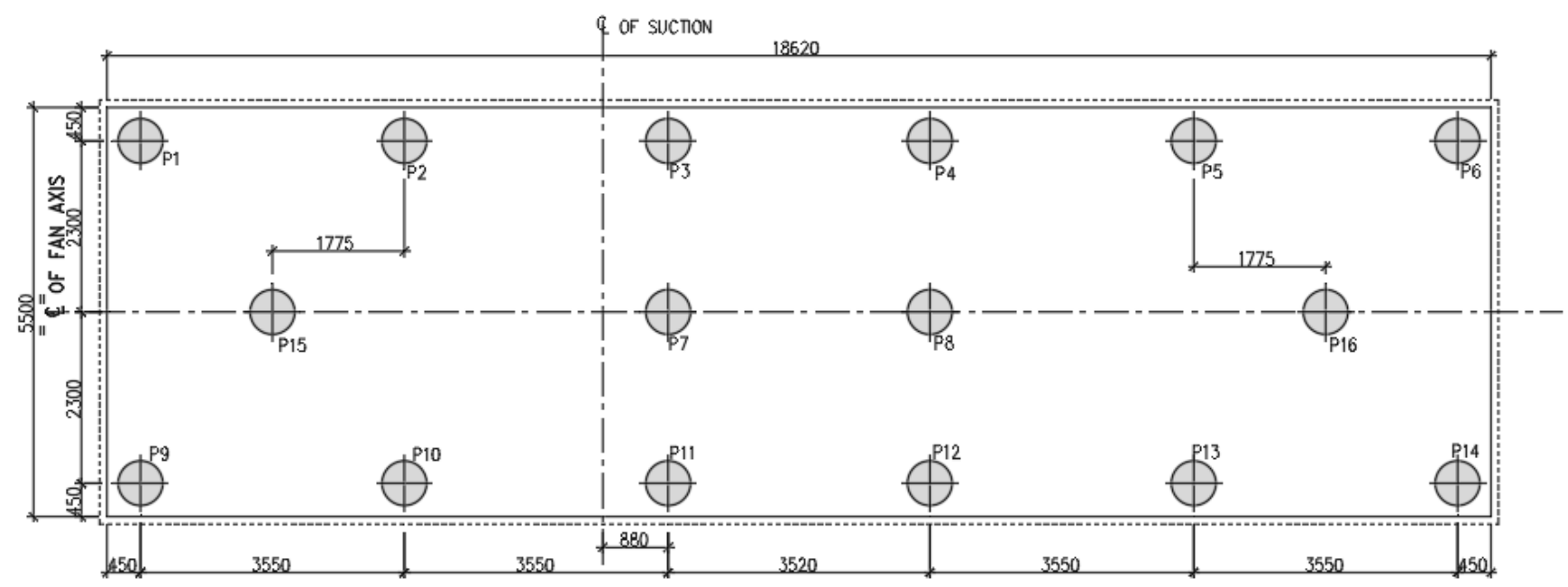

PILE LAYOUT

Figure 2. Pile-Layout.

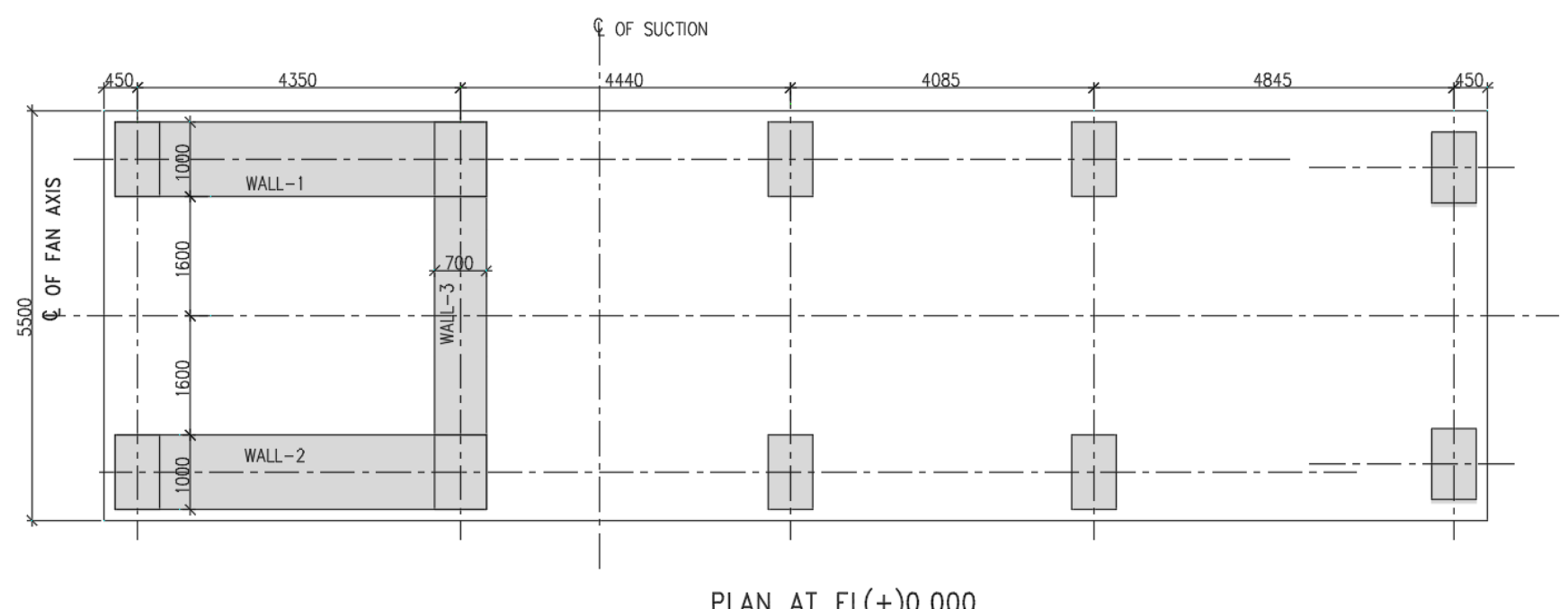

PLAN AT EL(+)0.000

Figure 3. Column and Wall Layout.

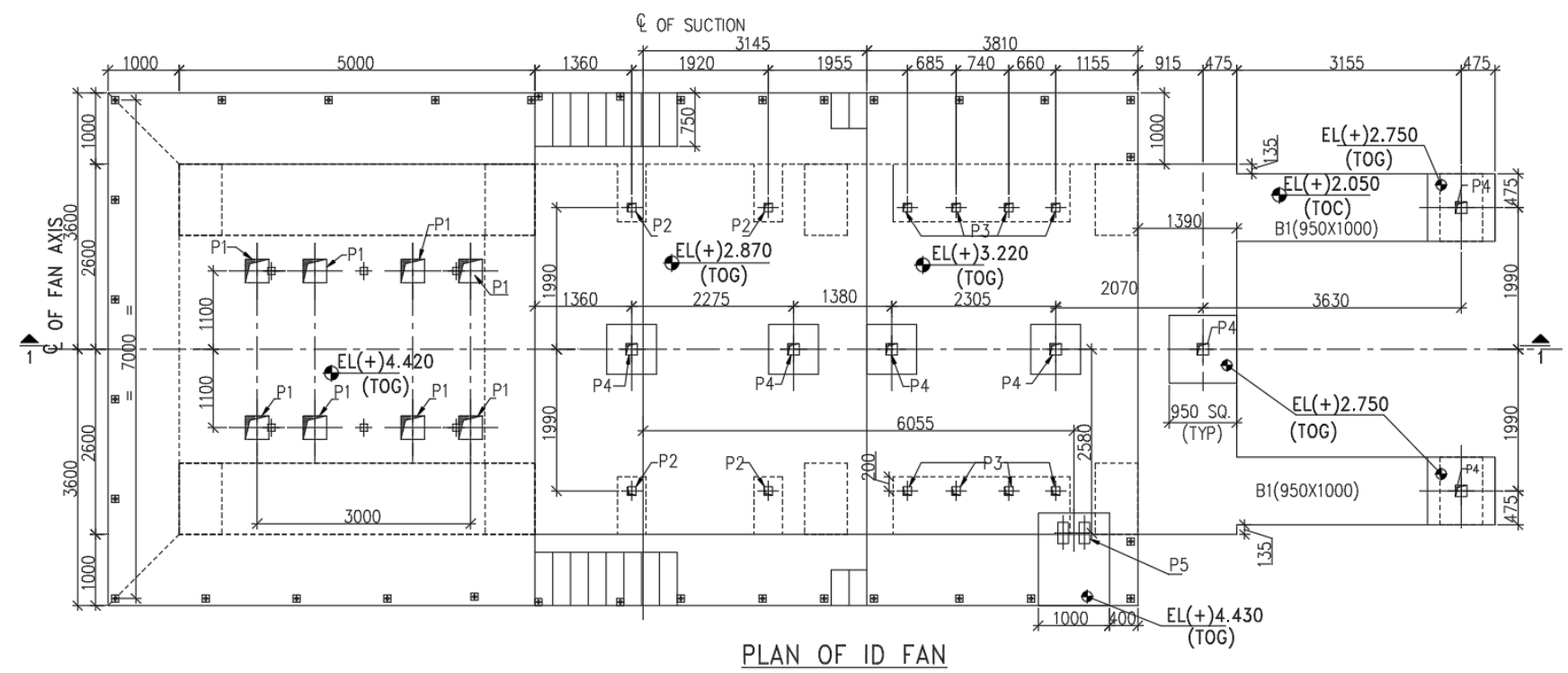

Figure 4. Foundation Top Deck Plan. 


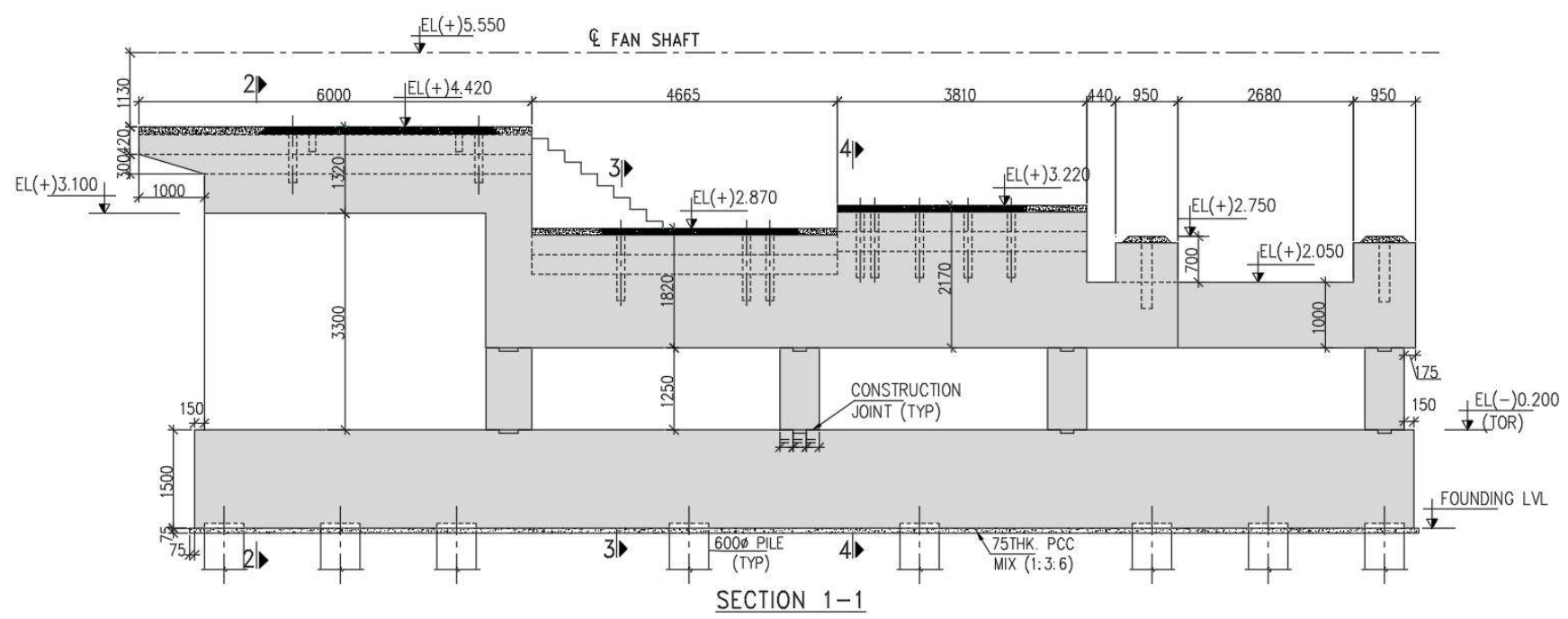

Figure 5. Foundation - Sectional Elevation.

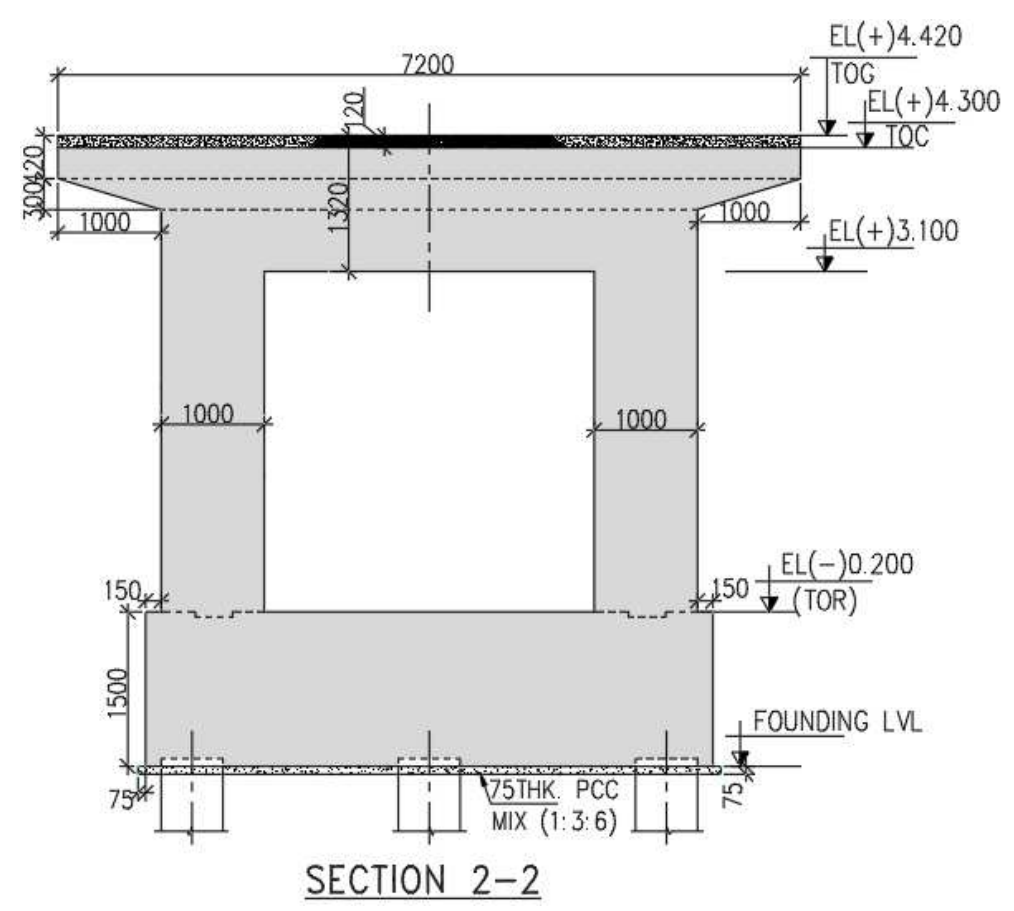

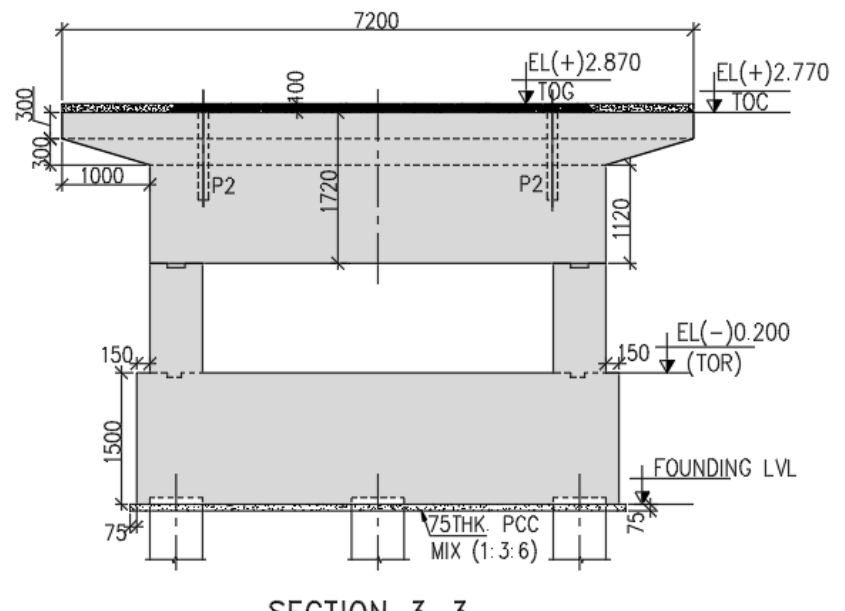

SECTION 3-3

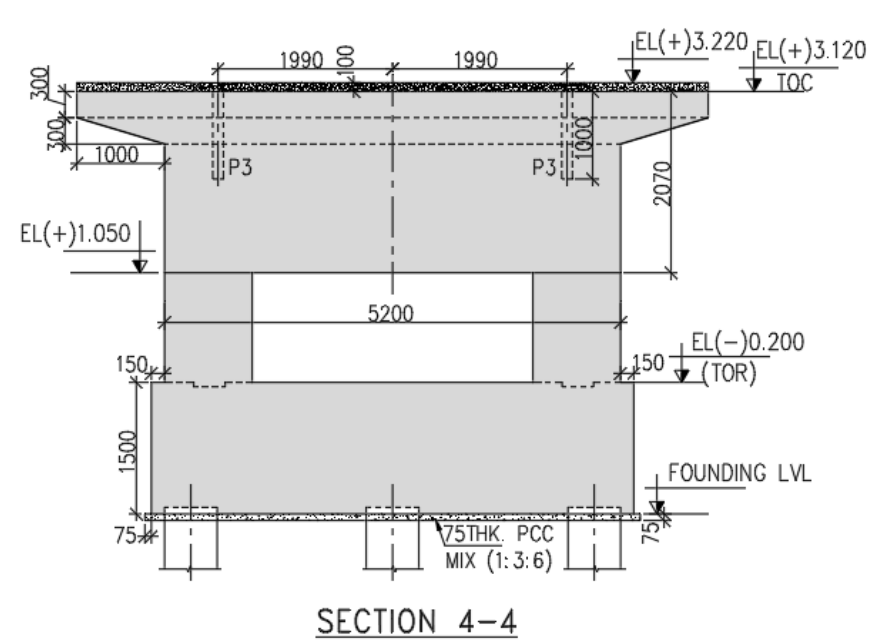

SECTION $4-4$

Figure 6. Foundation Cross Sections. 
The following data related to sub soil properties, concrete and foundation geometry are considered for the foundation design.

Table 1. Material and Geometric properties of concrete for foundation.

\begin{tabular}{ll}
\hline Property & Considered value \\
\hline Concrete Grade & M35 \\
Concrete Density & $25 \mathrm{KN} / \mathrm{m}^{3}$ \\
Concrete Dynamic Young's & Upper Value $=40000 \mathrm{~N} / \mathrm{mm}^{2}$ \\
Modulus [12, 13] & Lower Value $=33722 \mathrm{~N} / \mathrm{mm}^{2}$ \\
Raft Thickness & $1500 \mathrm{~mm}$ \\
Wall-1 and Wall-2 Thickness & $1000 \mathrm{~mm}$ \\
Wall-3 Thickness & $705 \mathrm{~mm}$ \\
Slab-1 height to bottom of slab & $3300 \mathrm{~mm}$ \\
Slab-2 height to bottom of slab & $1250 \mathrm{~mm}$ \\
Slab-3 height to bottom of slab & $1250 \mathrm{~mm}$ \\
Pile Vertical Stiffness [14] & $92956.3426 \mathrm{Ton} / \mathrm{m}$ \\
Pile Horizontal Stiffness [14] & $21991.4943 \mathrm{Ton} / \mathrm{m}$ \\
\hline
\end{tabular}

\subsubsection{Structural Model Sketches}

Finite element model is generated in ANSYS software with the above parameters, geometry and eigen solution is obtained for natural frequencies of the foundation system.

\subsubsection{Ansys Model Sketches}

From the FEM analysis following results obtained.

Foundation Frequency for Upper "E" value:

$\mathrm{X}$-direction $=8.37 \mathrm{~Hz}$ : Mode no. 2

$\mathrm{Z}$-direction $=6.47 \mathrm{~Hz}$ : Mode no. 1

Y-direction $=16.59 \mathrm{~Hz}$ : Mode no. 4

Foundation Frequency for Lower "E" value:

$\mathrm{X}$-direction $=8.26 \mathrm{~Hz}$ : Mode no. 2

Z-direction $=6.35 \mathrm{~Hz}$ : Mode no. 1

Y-direction $=16.24 \mathrm{~Hz}$ : Mode no. 4

The equipment operating frequency $=745 / 60=12.41 \mathrm{~Hz}$

The foundation frequencies are away from the equipment frequency: $9.9 \mathrm{~Hz}(0.8 * 12.41)$ To $14.9 \mathrm{~Hz}(1.2 * 12.41)$.

As per IS: 2974 [13].

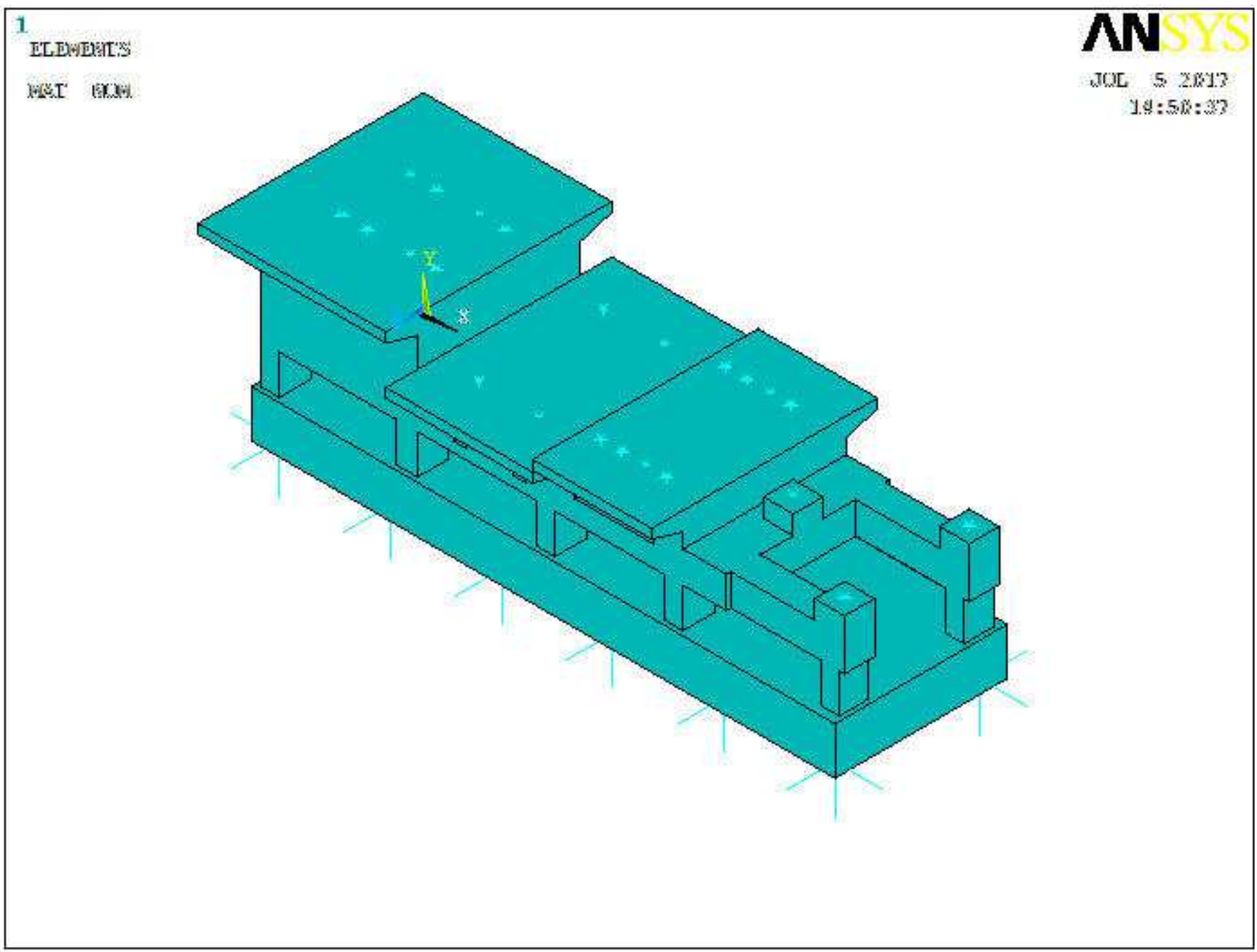

Figure 7. ANSYS - Solid Model. 


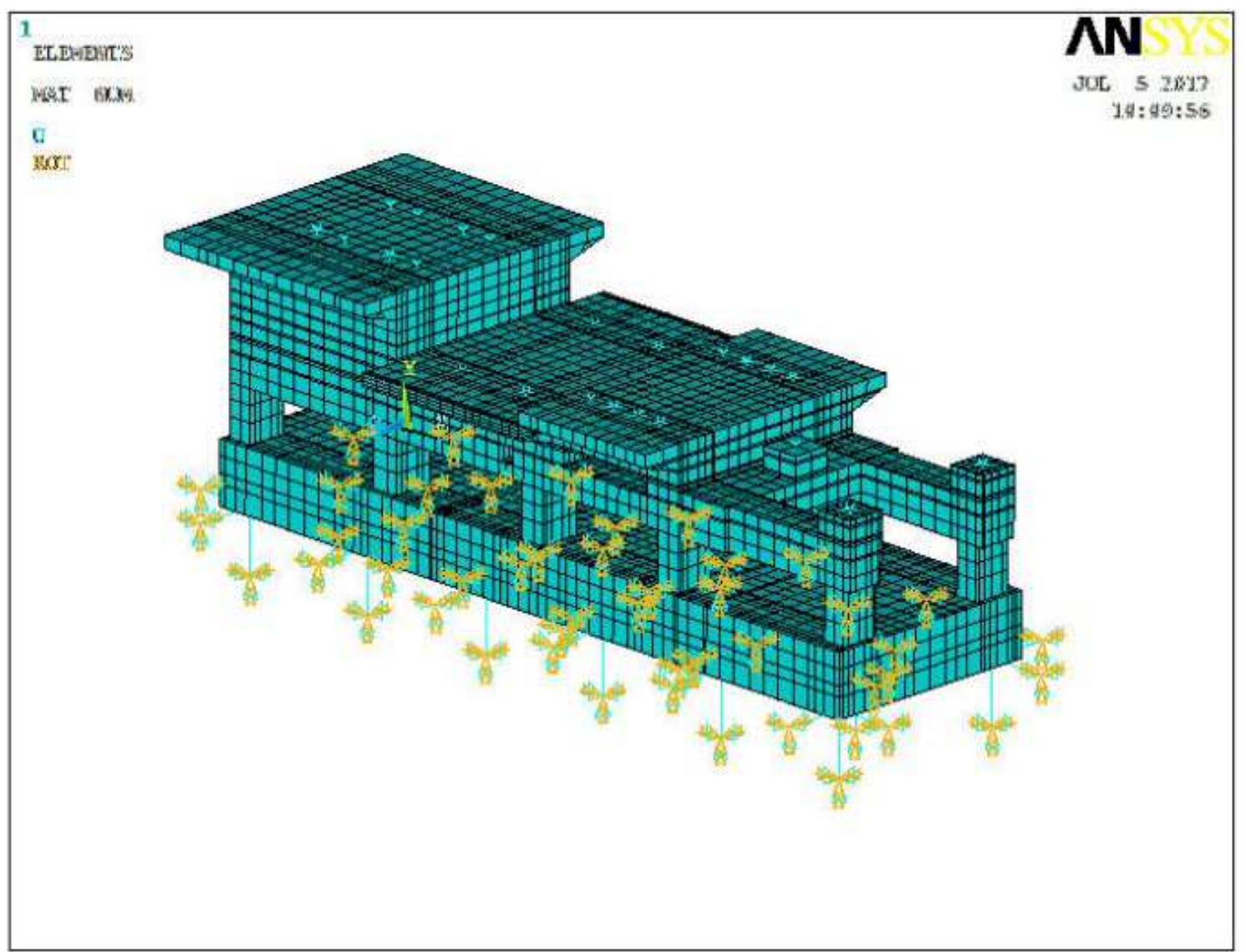

Figure 8. ANSYS - Solid Model-Element Mesh.

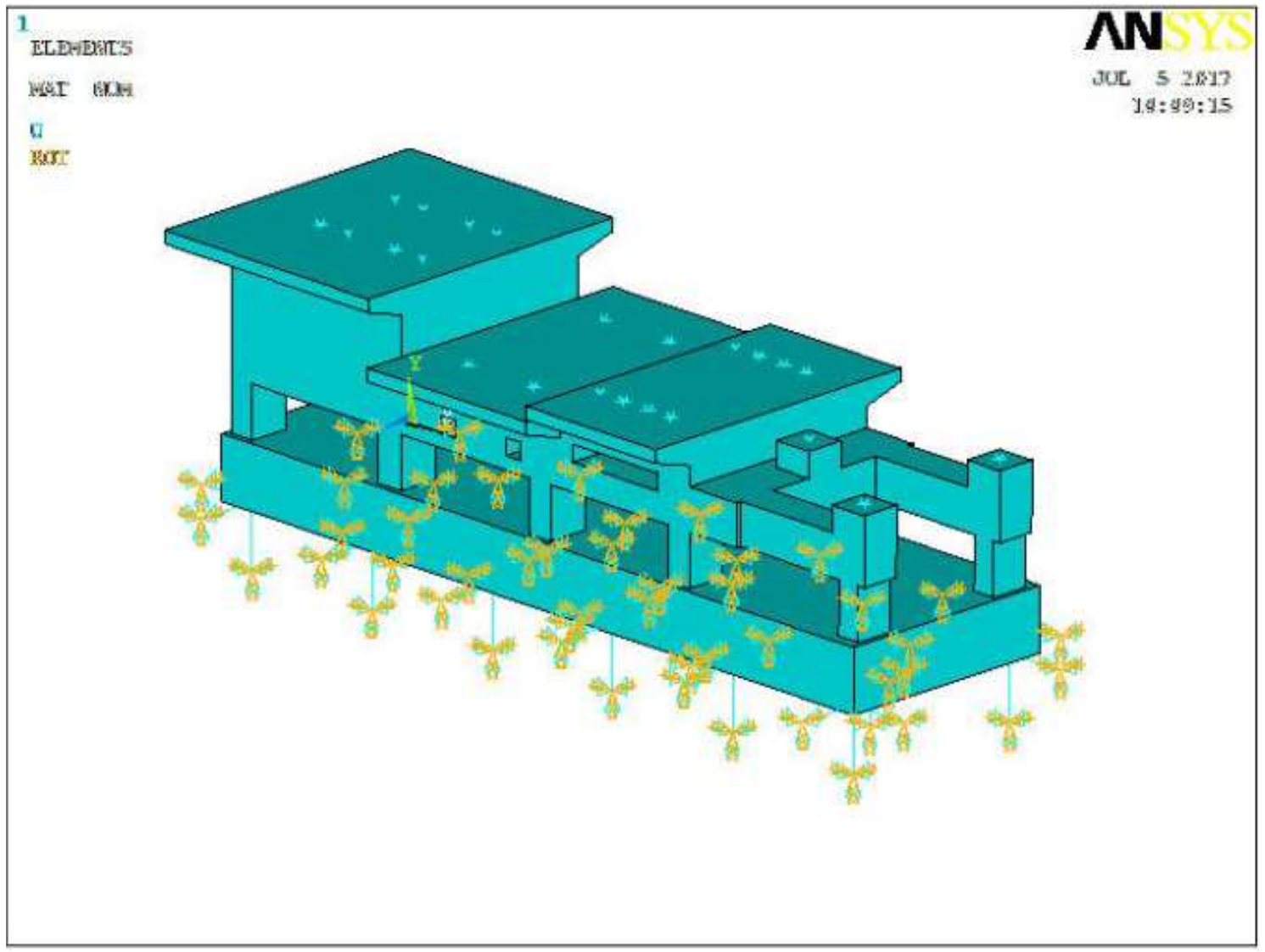

Figure 9. ANSYS - Solid Model Applied Boundary Conditions. 
The following results of above design would be compared with that of optimum solution obtained using Genetic Algorithms.

Table 2. Foundation FEM analysis output parameters for comparison with optimized solution output from GA's.

\begin{tabular}{lllllll}
\hline \multirow{2}{*}{$\begin{array}{l}\text { Concrete } \\
\text { Volume }\end{array}$} & \multicolumn{5}{l}{ Natural Frequency in Each Direction for solution obtained from manual trails } & \\
\cline { 2 - 7 } & $\begin{array}{l}\text { Along rotor } \\
\text { direction (X-Dir) }\end{array}$ & $\begin{array}{l}\text { Across rotor } \\
\text { direction (Z-Dir) }\end{array}$ & $\begin{array}{l}\text { Vertical direction } \\
\text { (Y-Dir) }\end{array}$ & $\begin{array}{l}\text { Rotation about } \\
\text { X-Axis (Rocking) }\end{array}$ & $\begin{array}{l}\text { Rotation about } \\
\text { Y-Axis (Yawing) }\end{array}$ & $\begin{array}{l}\text { Rotation about } \\
\text { Z-Axis (Pitching) }\end{array}$ \\
\hline $330 \mathrm{~m}^{3}$ & $8.38 \mathrm{~Hz}$ & $6.47 \mathrm{~Hz}$ & $16.25 \mathrm{~Hz}$ & $6.47 \mathrm{~Hz}$ & $9.93 \mathrm{~Hz}$ & $16.24 \mathrm{~Hz}$ \\
\hline
\end{tabular}

\subsection{Scope of Research}

Solution illustrated in the previous section is a result of many trails out of experience. During trails, it was noticed that foundation fundamental natural frequencies are falling very close to machine operating frequency causing close to resonance conditions. Some out of six fundamental frequencies are falling below the machine operating frequency, and some are falling above the machine operating frequency. So, the machine is neither completely over-tuned nor completely under-tuned. Under such circumstances, designing the foundation satisfying frequency separation criteria is an uphill task. This requires selection of right combination of member sizes, material parameters and foundation shape which satisfies the frequency separation criteria.

From the above trails it is observed that, frequency separation criteria being the constraint is directly influenced by assumed member sizes, material parameters and shape of the foundation. Many trails have failed in meeting the frequency separation criteria. However, it is also observed that, various possible combination of member sizes, material properties and foundation shape are forming solution to the foundation design satisfying both dynamic and static design criteria. Some are very conservative, and some are optimum solutions. Hence there is a scope for the foundation design optimization under such complex situations satisfying the dynamic criteria by keeping member sizes, material parameters and shape of the foundation as variables.

Principles of GA are applied for design optimization of ID fan foundation and an optimum solution is obtained using Genetic Algorithm's satisfying dynamic criteria and is compared with that obtained using manual trails. It is established that, solution obtained using Genetic algorithms is an optimum solution compared to present solutions being adopted out of industry practices.

\subsection{Dynamic Analysis of ID Fan Foundation in Genetic Algorithm}

In this work, Genetic algorithms are applied to obtain the suitable and optimum solution with member sizes, material parameters and shape of the foundation as variables and setting frequency as constraint criteria. As seen in chapter-2, application of GA's involves large number of trials with various possible options. This involves doing large number of solutions for the problem. Obtaining solutions using ANSYS finite element methods involves huge time and efforts for each population and is not practicable. Hence a simple method (Barkan's method) [8] yet gives close results is used for obtaining solutions for each population in Genetic algorithms.

\subsection{Application of GA's for ID Fan Design}

\subsubsection{Objective Function}

Principles of Genetic Algorithms are explained in-detail in ref. $[1,2]$. Similar principles are applied in finding an optimum solution for ID fan foundation design.

Objective function is represented as below.

$$
\text { Minimize, } f=S_{i=1}^{N} B_{i} D_{i} L
$$

Where, $\mathrm{f}=$ Total concrete volume of the ID fan foundation $\mathrm{B}_{\mathrm{i}}=$ Breadth of the $\mathrm{i}^{\text {th }}$ member.

$D_{i}=$ Depth of the $i^{\text {th }}$ member.

$\mathrm{L}_{\mathrm{i}}=$ Length of the $\mathrm{i}^{\text {th }}$ member.

$\mathrm{N}=$ Number of Members

subjected to following constraints.

Any natural frequency corresponding to primary mode shapes shall be

$$
<=0.8 x \text { Machine Operating Frequency. }
$$

Any natural frequency corresponding to primary mode shapes shall be

$$
>=1.2 x \text { Machine Operating Frequency. }
$$

Where machine (ID Fan) operating frequency $=745$ RPM or $12.417 \mathrm{~Hz}$.

In this case amplitude check is neglected for simplifying the problem solution for evaluating the fitness of every population. Generally, it is assumed that, a solution satisfying frequency criteria will also satisfy amplitude check criteria as well. However same is verified by full scale FEM model in ANSYS and amplitudes are compared with that of allowable values.

The constraints are expressed in normalized form as below.

Violation coefficient ' $\mathrm{C}$ ' for each population is computed in the following manner.

$$
\mathrm{C}=\sum_{k=1}^{m} C k
$$

where $\mathrm{k}=\mathrm{k}^{\text {th }}$ constraint and $\mathrm{k}=1,2, \ldots . \mathrm{m}$

where " $\mathrm{m}$ " = total number of constraints.

Now the modified objective function $\varnothing$ is written as

$$
\varnothing=f\left(1+K C^{n}\right)
$$

Where $\mathrm{n}=$ constant (Normally taken as 1.3 )

$\mathrm{K}=100$

Now the genetic algorithm is used to carry out unconstrained optimization of " $\varnothing$ ”.

\subsubsection{Design Variables}

Following design variables are considered in the 
optimization of the foundation design. The discrete values assigned for each variable are based on the previous experience and possible practicable values. Assigning inappropriate values lead to non-convergence of the solution and huge solution time. Sometimes the so obtained solution may be not practicable.

Raft Thickness (meters):

$0.750,0.850,0.900,1.000,1.100,1.250,1.300,1.400$,

$1.500,1.750,2.000,2.100,2.250,2.500,2.750,3.000$

Wall-1 and wall 2 Thickness (meters):

$0.450,0.500,0.550,0.600,0.650,0.700,0.750,0.800$,

$0.850,0.900,0.950,1.000,1.050,1.100,1.150,1.200$

Wall-3 Thickness (meters):

$0.300,0.325,0.375,0.400,0.425,0.450,0.475,0.500$,

$0.525,0.550,0.575,0.600,625,0.650,0.675,0.700$

Slab-1 height to bottom of slab (meters):

3.6, 3.5, 3.4, 3.3, 3.2, 3.1, 3.0, 2.9, 2.8, 2.7, 2.6, 2.5, 2.4, $2.3,2.2,2.1$

Slab-2 Height to bottom of slab (meters):

$2.0,1.9,1.8,1.75,1.7,1.65,1.6,1.5,1.4,1.3,1.25,1.2$,

$1.15,1.1,1.05,1.0$

Slab-3 height to bottom of slab (meters):

$2.5,2.4,2.3,2.25,2.2,2.15,2.1,2.0,1.9,1.8,1.75,1.7$,

$1.65,1.6,1.55,1.5$

Pile Fixity depth (meters):

$3.5,3.5,3.5,3.5,3.5,3.5,3.5,3.5,3.5,3.5,3.5,3.5,3.5$,

$3.5,3.5,3.5$

Dynamic Modulus of Concrete (Ton $\left./ \mathrm{m}^{2}\right)$ :

2850000, 2900000, 3000000, 3100000, 3150000, $3200000,3250000,3300000,3350000,3400000,3450000$, 3500000, 3550000, 3600000, 3650000, 3700000

Pile Vertical Stiffness (Ton/m):

$85000,85000,85000,85000,90000,90000,90000$, 90000, 93000, 93000, 93000, 93000, 100000, 100000, 100000, 100000

Pile Horizontal Stiffness (Ton $/ \mathrm{m}$ ):

20000, 20000, 20000, 20000, 21000, 21000, 21000, 21000, 22000, 22000, 22000, 22000, 23000, 23000, 23000, 23000

The design variables are coded in binary form. A four-bit binary substring is used to code each variable in which case a variable can take sixteen discrete values. Hence forty-bit concatenated string is adopted to represent above design variables.

The number of populations depends on the importance of the problem and the complexity involved. The number should be even to facilitate mating. In this example number of populations chosen are 100 numbers as there is complexity in the problem solution with more number variables. The strings representing individuals in the population are generated randomly. Strings are decoded and corresponding parameter from the above defined list are obtained. The structure is then analyzed using Barkan's method and eigen solution is obtained for each population for above parameters. From the solution, foundation natural frequencies are compared with the constraints criteria as mentioned in equation (2) and (3). The corresponding violation co-efficient is calculated for each population.
Knowing foundation concrete volume, "f" and violation coefficient " $C$ " now values of the modified function ' $\varnothing$ ' are calculated using eq. (5) for each population and ' $\varnothing$ ' is converted into corresponding fitness values. The conversion of ' $\varnothing$ ' values into corresponding fitness values (F) is carried out in such a way that the best individuals have maximum fitness. For minimization problems ' $\varnothing$ ' should be subtracted from a large constant, so that the fitness values are non-negative. In the present formulation it is done as below for all the populations.

$$
F_{k}=\left[f_{\max }+f_{\min }\right]-f_{k} k=1,2, \ldots . . n
$$

Where " $n$ " is the total number of populations. $F_{k}$ is the fitness of the $\mathrm{k}^{\text {th }}$ individual. Having obtained the fitness values for all populations, populations for the next generation are generated which are the off springs of the current generation based on their fitness. Only two genetic operators, reproduction and two-point cross over are used to generate the population for the next generation. The reproduction operator selects the best fit individuals from the current population and places them in a mating pool. Highly fit individuals get more copies and less fit individuals get lower copies or get deleted. As the number of individuals in the next generation are also same, the worst fit individuals die off. The reproduction process is carried out in the following manner.

The factor $\left(\mathrm{F}_{\mathrm{k}} / \mathrm{F}_{\mathrm{avg}}\right)$ is computed for all the individuals, where $\mathrm{F}_{\text {avg }}$ is average fitness. This factor is the expected count in the mating. It is converted into an actual count by appropriately rounding off so that the individuals get copies in the mating pool proportional to their fitness. A mating pool is created, where the individuals having good fitness get copies 1 or 2 and individuals with poor fitness die off. This process of reproduction confirms the Darwinian principle of survival of the fittest.

For carrying out cross over operator, the pairs are selected randomly. Two cross sites are chosen randomly along the length of the string for each pair. Now the information (binary code) is exchanged between these two sites for the mated pair.

Set of new 100 populations are generated after cross over operation, which is population set of generation - 2. The same process is repeated for generation - 2 and so on till 100 generations.

As one proceeds with more generations, there may not be much improvement in the population's fitness and the best individual may not change for subsequent populations. As the generations progresses the population gets filled by more fit individuals with only slight deviation from the fitness of the best individual so far found and the average fitness comes very close to the fitness of the best individual. Number of generations is left to the personal interest. If the satisfied result is obtained, the iteration can be stopped, or it can be stopped when there is no significant improvement in the performance from generation to generation for a particular number of generations. In this case iterations are carried until 100 generations.

From the study of the 100 generations, optimum solution is identified as population number 58 in generation number-77. The solution output of entire generation-77 is listed in table 4 .

The output of population-58 in generation- 77 is tabulated in the below table. 
Table 3. Output parameters from optimized solution from GA's.

\begin{tabular}{lllllll}
\hline \multirow{2}{*}{$\begin{array}{l}\text { Concrete } \\
\text { Volume }\end{array}$} & \multicolumn{2}{l}{ Natural Frequency in Each Direction for } & optimized solution from GA's & & \\
\cline { 2 - 7 } & $\begin{array}{l}\text { Along rotor } \\
\text { direction (X-Dir) }\end{array}$ & $\begin{array}{l}\text { Across rotor } \\
\text { direction (Z-Dir) }\end{array}$ & $\begin{array}{l}\text { Vertical direction } \\
\text { (Y-Dir) }\end{array}$ & $\begin{array}{l}\text { Rotation about } \\
\text { X-Axis (Rocking) }\end{array}$ & $\begin{array}{l}\text { Rotation about } \\
\text { Y-Axis (Yawing) }\end{array}$ & $\begin{array}{l}\text { Rotation about } \\
\text { Z-Axis (Pitching) }\end{array}$ \\
\hline $295.20 \mathrm{~m}^{3}$ & $9.38 \mathrm{~Hz}$ & $9.38 \mathrm{~Hz}$ & $19.33 \mathrm{~Hz}$ & $7.31 \mathrm{~Hz}$ & $9.91 \mathrm{~Hz}$ & $15.07 \mathrm{~Hz}$ \\
\hline
\end{tabular}

The input parameters related to sub soil properties, concrete and foundation geometry corresponding to population-58 in generation-77 are tabulated in the below table.

Table 4. Input Parameters.

\begin{tabular}{ll}
\hline Property & Considered value \\
\hline Concrete Grade & $\mathrm{M} 30$ \\
Concrete Density & $25 \mathrm{KN} / \mathrm{m}^{3}$ \\
Concrete Dynamic Young's Modulus [12, 13] & $32000 \mathrm{~N} / \mathrm{mm}^{2}$ \\
Raft Thickness & $750 \mathrm{~mm}$ \\
Wall-1 and Wall-2 Thickness & $1050 \mathrm{~mm}$ \\
Wall-3 Thickness & $675 \mathrm{~mm}$ \\
Slab-1 height to bottom of slab & $2200 \mathrm{~mm}$ \\
Slab-2 height to bottom of slab & $1900 \mathrm{~mm}$ \\
Slab-3 height to bottom of slab & $2300 \mathrm{~mm}$ \\
Pile Vertical Stiffness [14] & $85000 \mathrm{Ton} / \mathrm{m}$ \\
Pile Horizontal Stiffness [14] & $20000 \mathrm{Ton} / \mathrm{m}$ \\
\hline
\end{tabular}

The general arrangement of the foundation corresponding to optimum solution (population-58 in generation-77) obtained from GA is shown in below figures.

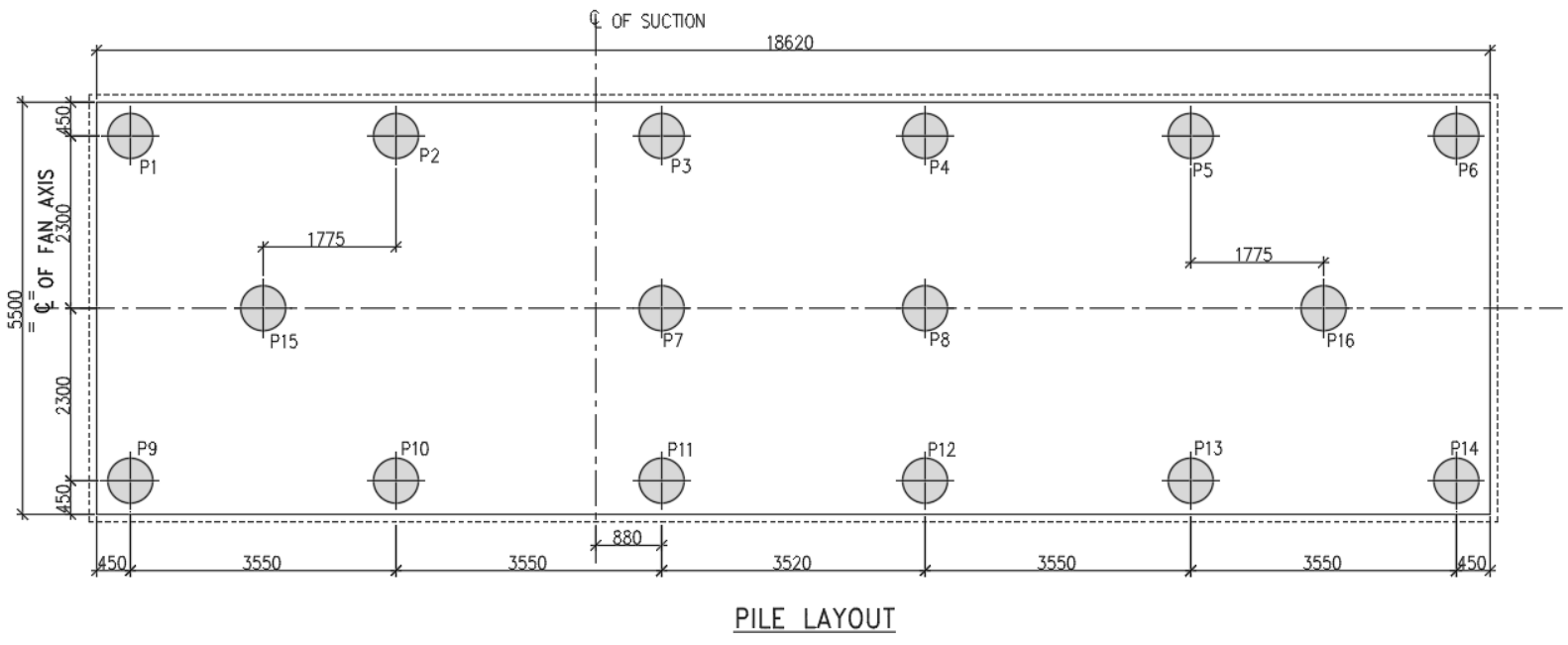

Figure 10. Foundation Pile Layout.

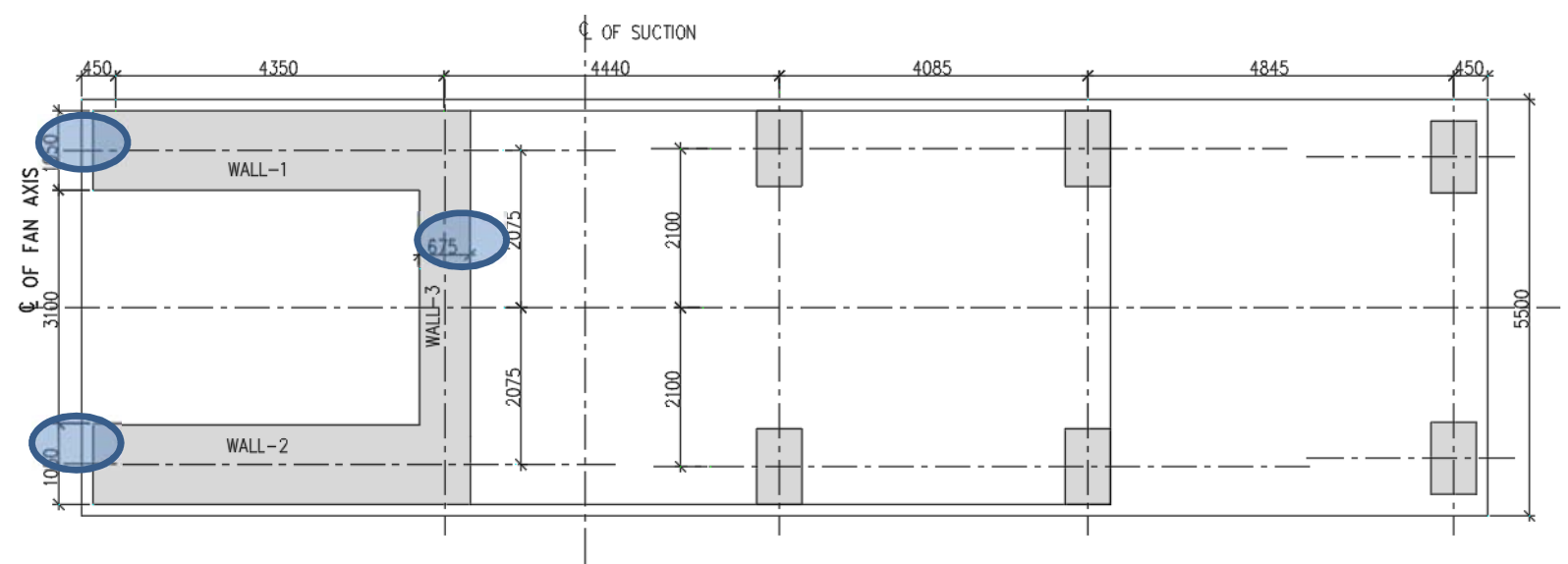

PLAN AT EL(t)0.000

Figure 11. Foundation Column and Wall Layout. 


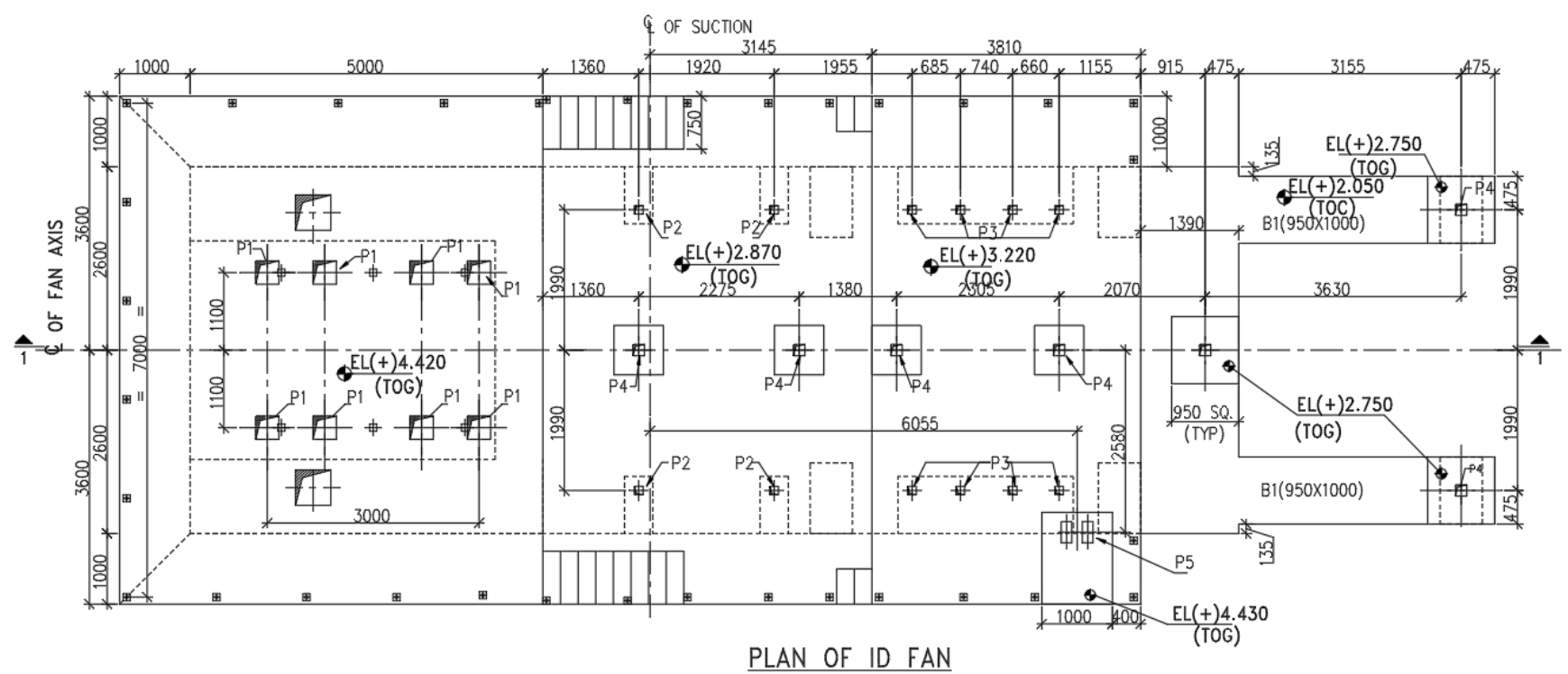

Figure 12. Foundation Top Deck Plan.

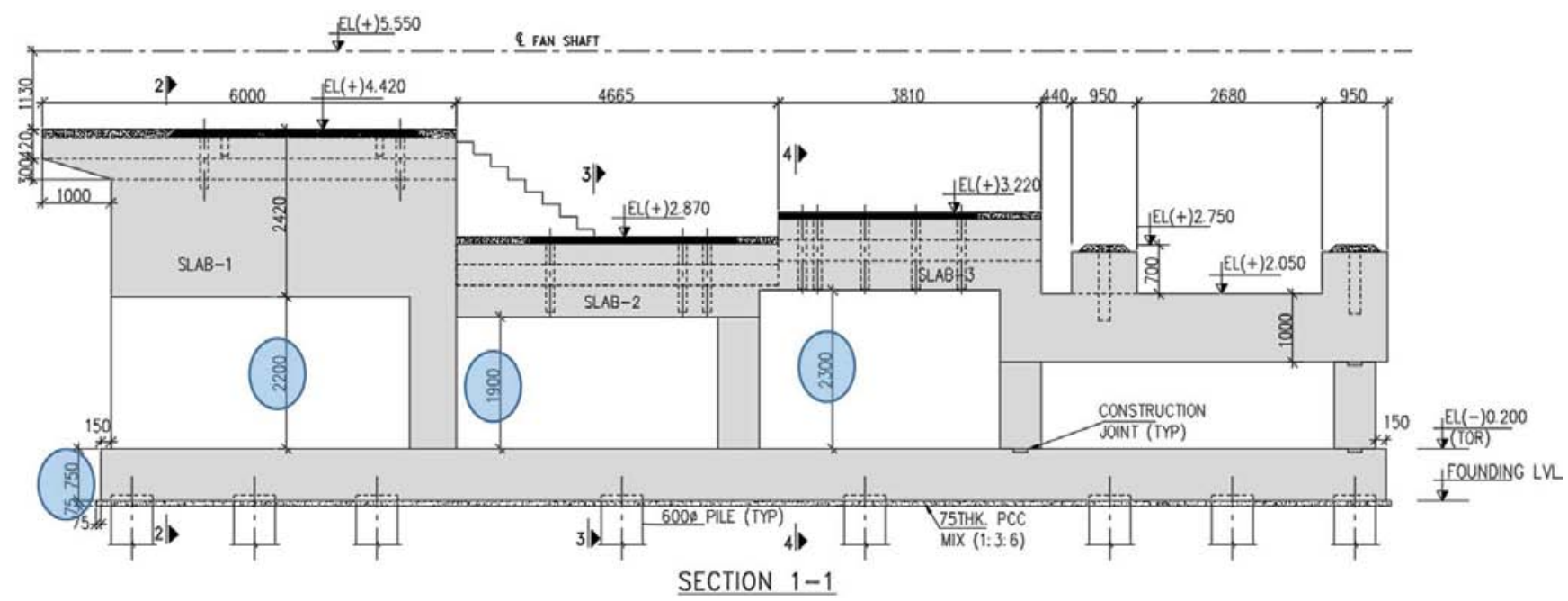

Geometric Variables Considered in the problem

Figure 13. Foundation - Sectional Elevation.

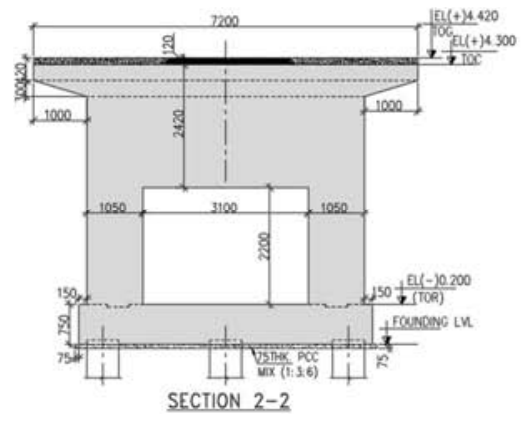

SECTION 2-2

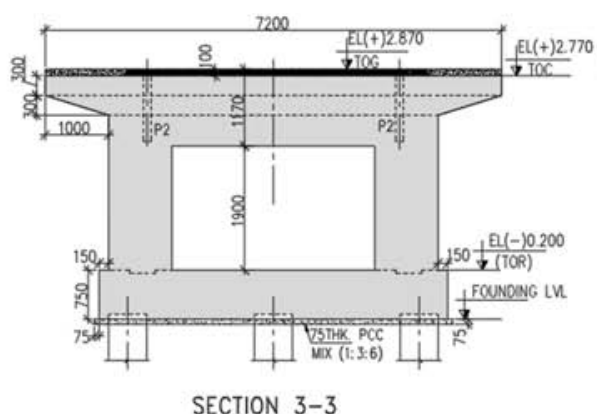

SECTION 3-3

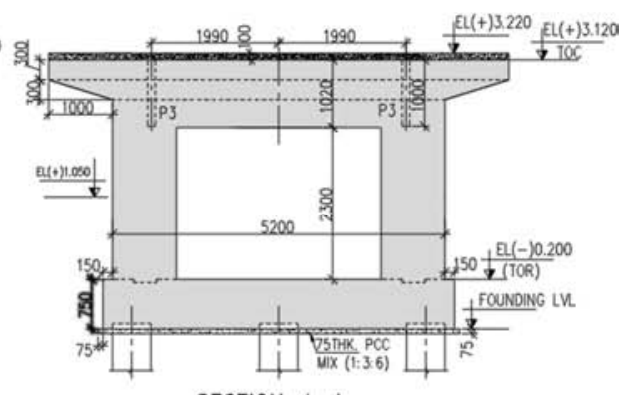

SECTION 4-4

Figure 14. Foundation Cross Sections.

\subsection{Results Comparison}

From the tables 2 and 3, it is noted that optimum solution obtained using GA's is having concrete volume of $295.20 \mathrm{~m}^{3}$ as against $330 \mathrm{~m}^{3}$ of solution obtained using manual trails. The optimum solution obtained using GA's is meeting the specified constraints with respect to natural frequencies. This solution is based on the discrete input parameters which are practical to adopt in field. Thus, GA's has provided an optimum solution with $34.80 \mathrm{~m}^{3}$ savings in concrete volume which is $10.60 \%$ lesser. Hence it is established that, GA's can be successfully used for optimization of fan foundations which are practicable 
to construct and operate in real time. However as mentioned in section 4.6.1, the optimum solution obtained using GA's is cross checked for displacement amplitude criteria using FEM model in ANSYS software in the next section.

Table 5. Generation - 77 Output.

\begin{tabular}{|c|c|c|c|c|c|c|}
\hline \multirow{2}{*}{$\begin{array}{l}\text { Population } \\
\text { Number }\end{array}$} & \multirow{2}{*}{$\begin{array}{l}\text { Concrete } \\
\text { Volume }\end{array}$} & $\begin{array}{l}\text { Vertical direction } \\
\text { (Y-Dir) }\end{array}$ & $\begin{array}{l}\text { Rotation about } \\
\text { Y-Axis (Yawing) }\end{array}$ & $\begin{array}{l}\text { Along rotor } \\
\text { direction (X-Dir) }\end{array}$ & $\begin{array}{l}\text { Rotation about } \\
\text { Z-Axis (Pitching) }\end{array}$ & $\begin{array}{l}\text { Across rotor } \\
\text { direction (Z-Dir) }\end{array}$ \\
\hline & & Wnz_1 & Wns_1 & Wx_1 & WTy_1 & Wy_1 \\
\hline 1 & 321.98 & 18.65 & 10.38 & 9.7 & 14.57 & 9.7 \\
\hline 2 & 382.65 & 18.81 & 9.07 & 8.41 & 14.52 & 8.41 \\
\hline 3 & 498.73 & 16.77 & 8.14 & 7.5 & 12.47 & 7.5 \\
\hline 4 & 456.74 & 17.43 & 8.8 & 8.18 & 12.94 & 8.18 \\
\hline 5 & 310.68 & 18.93 & 10.13 & 9.41 & 15.04 & 9.41 \\
\hline 7 & 297.32 & 19.27 & 10.56 & 9.58 & 15.63 & 9.58 \\
\hline 8 & 299.74 & 19.21 & 10.49 & 9.55 & 15.55 & 9.55 \\
\hline 9 & 302.77 & 19.13 & 10.12 & 9.51 & 15.03 & 9.51 \\
\hline 10 & 448.28 & 16.95 & 8.98 & 8.24 & 12.98 & 8.24 \\
\hline 11 & 447.29 & 16.97 & 8.99 & 8.25 & 12.98 & 8.25 \\
\hline 12 & 301.84 & 20.78 & 10.72 & 9.96 & 16.49 & 9.96 \\
\hline 13 & 350.88 & 19.52 & 9.94 & 9.15 & 15.26 & 9.15 \\
\hline 16 & 284.01 & 21.3 & 10.39 & 9.52 & 17.1 & 9.52 \\
\hline 17 & 314.63 & 19.7 & 9.94 & 9.13 & 15.62 & 9.13 \\
\hline 18 & 457.27 & 16.06 & 9.1 & 8.36 & 12.23 & 8.36 \\
\hline 19 & 322.14 & 20.23 & 10.28 & 9.49 & 16.03 & 9.49 \\
\hline 20 & 341.37 & 19.74 & 10.16 & 9.26 & 15.74 & 9.26 \\
\hline 21 & 368.38 & 19.12 & 9.15 & 8.55 & 14.71 & 8.55 \\
\hline 22 & 313.82 & 19.72 & 10.91 & 9.81 & 15.99 & 9.81 \\
\hline 23 & 400.16 & 18.46 & 9.31 & 8.46 & 14.35 & 8.46 \\
\hline 24 & 313.77 & 19.4 & 10.09 & 9.37 & 15.38 & 9.37 \\
\hline 25 & 543.73 & 15.31 & 8.11 & 7.4 & 11.3 & 7.4 \\
\hline 26 & 518.13 & 15.65 & 8.28 & 7.56 & 11.68 & 7.56 \\
\hline 27 & 330.17 & 19.31 & 9.99 & 9.39 & 14.94 & 9.39 \\
\hline 28 & 288.3 & 19.52 & 10.2 & 9.47 & 15.46 & 9.47 \\
\hline 29 & 311.99 & 18.9 & 10.37 & 9.39 & 15.21 & 9.39 \\
\hline 30 & 449.14 & 17.56 & 8.89 & 8.05 & 13.53 & 8.05 \\
\hline 33 & 305.91 & 19.6 & 10.43 & 9.69 & 15.36 & 9.69 \\
\hline 34 & 325.91 & 19.41 & 10.48 & 9.65 & 15.45 & 9.65 \\
\hline 35 & 342.98 & 18.69 & 10.03 & 9.24 & 14.66 & 9.24 \\
\hline 36 & 313.08 & 19.74 & 10.68 & 9.82 & 15.78 & 9.82 \\
\hline 37 & 289.52 & 21.13 & 10.01 & 9.45 & 16.52 & 9.45 \\
\hline 38 & 368.38 & 17.63 & 9.3 & 8.55 & 13.7 & 8.55 \\
\hline 39 & 374.17 & 17.51 & 9.32 & 8.49 & 13.84 & 8.49 \\
\hline 40 & 326.1 & 20.12 & 9.81 & 9 & 16 & 9 \\
\hline 41 & 433.52 & 17.2 & 8.76 & 7.97 & 13.21 & 7.97 \\
\hline 42 & 358.28 & 19.35 & 10.05 & 9.28 & 14.99 & 9.28 \\
\hline 43 & 334.85 & 19.9 & 10.52 & 9.55 & 15.82 & 9.55 \\
\hline 44 & 296.71 & 20.92 & 10.37 & 9.59 & 16.82 & 9.59 \\
\hline 45 & 360.08 & 18.32 & 9.57 & 8.85 & 14.22 & 8.85 \\
\hline 46 & 326.79 & 19.39 & 9.68 & 8.99 & 15.17 & 8.99 \\
\hline 47 & 373.32 & 18.04 & 9.9 & 9.12 & 13.95 & 9.12 \\
\hline 48 & 539.27 & 15.62 & 8.14 & 7.42 & 11.44 & 7.42 \\
\hline 49 & 401.49 & 18.43 & 8.98 & 8.24 & 14.35 & 8.24 \\
\hline 50 & 306.88 & 19.58 & 10.24 & 9.46 & 15.58 & 9.46 \\
\hline 51 & 340.6 & 19.76 & 9.98 & 9.27 & 15.46 & 9.27 \\
\hline 52 & 483.72 & 16.13 & 8.95 & 8.15 & 12.09 & 8.15 \\
\hline 53 & 434.35 & 17.18 & 8.95 & 8.17 & 13.18 & 8.17 \\
\hline 54 & 410.32 & 18.26 & 9.14 & 8.37 & 14.06 & 8.37 \\
\hline 55 & 378.81 & 17.93 & 9.12 & 8.45 & 13.92 & 8.45 \\
\hline 56 & 449.01 & 16.19 & 9.01 & 8.24 & 12.27 & 8.24 \\
\hline 57 & 316.42 & 18.79 & 10.61 & 9.77 & 14.87 & 9.77 \\
\hline 58 & 295.2 & 19.33 & 9.91 & 9.38 & 15.07 & 9.38 \\
\hline 59 & 482.24 & 16.42 & 8.35 & 7.61 & 12.38 & 7.61 \\
\hline 60 & 343.05 & 18.69 & 9.69 & 9.03 & 14.55 & 9.03 \\
\hline
\end{tabular}




\begin{tabular}{|c|c|c|c|c|c|c|}
\hline \multirow{2}{*}{$\begin{array}{l}\text { Population } \\
\text { Number }\end{array}$} & \multirow{2}{*}{$\begin{array}{l}\text { Concrete } \\
\text { Volume }\end{array}$} & \multirow{2}{*}{$\begin{array}{l}\text { Vertical direction } \\
\text { (Y-Dir) } \\
\text { Wnz_1 } \\
\end{array}$} & \multirow{2}{*}{$\begin{array}{l}\text { Rotation about } \\
\text { Y-Axis (Yawing) } \\
\text { Wns_1 } \\
\end{array}$} & \multirow{2}{*}{$\begin{array}{l}\begin{array}{l}\text { Along rotor } \\
\text { direction (X-Dir) }\end{array} \\
\text { Wx_1 }\end{array}$} & \multirow{2}{*}{$\begin{array}{l}\text { Rotation about } \\
\text { Z-Axis (Pitching) } \\
\text { WTy_1 } \\
\end{array}$} & \multirow{2}{*}{$\begin{array}{l}\begin{array}{l}\text { Across rotor } \\
\text { direction (Z-Dir) }\end{array} \\
\text { Wy_1 }\end{array}$} \\
\hline & & & & & & \\
\hline 61 & 468.99 & 15.89 & 8.91 & 8.08 & 12.1 & 8.08 \\
\hline 62 & 398.65 & 17.05 & 8.96 & 8.27 & 13.06 & 8.27 \\
\hline 63 & 407.05 & 17.67 & 9.1 & 8.4 & 13.6 & 8.4 \\
\hline 64 & 426.51 & 17.96 & 9.29 & 8.42 & 13.93 & 8.42 \\
\hline 65 & 519.38 & 15.19 & 8.61 & 7.9 & 11.17 & 7.9 \\
\hline 66 & 364.93 & 18.51 & 10.03 & 9.21 & 14.47 & 9.21 \\
\hline 67 & 266.67 & 21.84 & 10.75 & 9.77 & 17.71 & 9.77 \\
\hline 68 & 349.78 & 18.02 & 10.2 & 9.37 & 14.21 & 9.37 \\
\hline 69 & 368.45 & 18.14 & 9.45 & 8.76 & 14.04 & 8.76 \\
\hline 70 & 431.52 & 16.95 & 8.75 & 7.99 & 13.02 & 7.99 \\
\hline 71 & 335.76 & 19.17 & 9.91 & 9.11 & 15.2 & 9.11 \\
\hline 72 & 350.42 & 18 & 9.27 & 8.73 & 13.83 & 8.73 \\
\hline 73 & 318.62 & 19.28 & 10.24 & 9.53 & 15.2 & 9.53 \\
\hline 74 & 417.06 & 16.72 & 9.33 & 8.7 & 12.72 & 8.7 \\
\hline 75 & 420.75 & 16.65 & 9.16 & 8.47 & 12.62 & 8.47 \\
\hline 76 & 444.4 & 17.01 & 9.08 & 8.46 & 12.72 & 8.46 \\
\hline 77 & 453.56 & 16.59 & 8.99 & 8.39 & 12.39 & 8.39 \\
\hline 78 & 431.41 & 16.95 & 9.37 & 8.57 & 13.1 & 8.57 \\
\hline 79 & 441.18 & 16.79 & 9.23 & 8.49 & 12.82 & 8.49 \\
\hline 80 & 441.18 & 16.79 & 9.23 & 8.49 & 12.82 & 8.49 \\
\hline 81 & 371.93 & 18.36 & 9.79 & 8.93 & 14.39 & 8.93 \\
\hline 82 & 530.84 & 15.73 & 8.06 & 7.48 & 11.46 & 7.48 \\
\hline 83 & 352.96 & 18.47 & 9.63 & 8.71 & 14.67 & 8.71 \\
\hline 84 & 290.11 & 20.03 & 10.62 & 9.9 & 15.79 & 9.9 \\
\hline 85 & 302.59 & 20.02 & 10.75 & 9.95 & 16.01 & 9.95 \\
\hline 86 & 333.34 & 19.94 & 10.48 & 9.56 & 15.92 & 9.56 \\
\hline 87 & 452.05 & 16.61 & 9.03 & 8.21 & 12.71 & 8.21 \\
\hline 88 & 358.87 & 18.64 & 9.66 & 8.86 & 14.6 & 8.86 \\
\hline 89 & 304.87 & 19.95 & 10.08 & 9.25 & 16.02 & 9.25 \\
\hline 90 & 474.08 & 17.15 & 9.01 & 8.23 & 12.96 & 8.23 \\
\hline 91 & 511.56 & 15.73 & 8.61 & 7.95 & 11.61 & 7.95 \\
\hline 92 & 429.76 & 16.5 & 9.23 & 8.4 & 12.76 & 8.4 \\
\hline 93 & 331.72 & 19.27 & 9.72 & 8.94 & 15.22 & 8.94 \\
\hline 94 & 323.61 & 20.19 & 10.02 & 9.25 & 15.89 & 9.25 \\
\hline 95 & 477.8 & 15.76 & 8.94 & 8.2 & 11.77 & 8.2 \\
\hline 96 & 301.45 & 19.16 & 10.3 & 9.75 & 14.92 & 9.75 \\
\hline 97 & 329.1 & 18.48 & 10.11 & 9.4 & 14.48 & 9.4 \\
\hline 98 & 426.68 & 17.32 & 9.26 & 8.61 & 13.1 & 8.61 \\
\hline 99 & 425.36 & 17.34 & 8.71 & 8.04 & 13.21 & 8.04 \\
\hline 100 & 522.06 & 16.44 & 8.58 & 7.88 & 12.07 & 7.88 \\
\hline
\end{tabular}

Table 5. Continued.

\begin{tabular}{|c|c|c|c|c|}
\hline Population Number & $\begin{array}{l}\text { Rotation about } \mathrm{X} \text {-Axis (Rocking) } \\
\text { WTx_1 }\end{array}$ & $\begin{array}{l}\text { Whether all Constraints } \\
\text { Satisfied...? }\end{array}$ & $\begin{array}{l}\text { Concrete Volume of } \\
\text { Possible Solution }\end{array}$ & $\begin{array}{l}\text { Least of all Possible } \\
\text { Solution }\end{array}$ \\
\hline 1 & 6.98 & FALSE & - & 295.2 \\
\hline 2 & 6.83 & TRUE & 382.65 & \\
\hline 3 & 5.66 & TRUE & 498.73 & \\
\hline 4 & 5.91 & TRUE & 456.74 & \\
\hline 5 & 7.25 & FALSE & - & \\
\hline 6 & 6.96 & TRUE & 346.38 & \\
\hline 7 & 7.49 & FALSE & - & \\
\hline 8 & 7.47 & FALSE & - & \\
\hline 9 & 7.28 & FALSE & - & \\
\hline 10 & 5.99 & TRUE & 448.28 & \\
\hline 11 & 6 & TRUE & 447.29 & \\
\hline 12 & 7.96 & FALSE & - & \\
\hline 13 & 7.21 & FALSE & - & \\
\hline 14 & 6.45 & TRUE & 428.16 & \\
\hline 15 & 5.77 & TRUE & 429.92 & \\
\hline 16 & 8.22 & FALSE & - & \\
\hline 17 & 7.45 & FALSE & - & \\
\hline 18 & 5.63 & TRUE & 457.27 & \\
\hline 19 & 7.67 & FALSE & - & \\
\hline 20 & 7.48 & FALSE & - & \\
\hline
\end{tabular}




\begin{tabular}{|c|c|c|c|c|}
\hline \multirow{2}{*}{ Population Number } & \multirow{2}{*}{$\begin{array}{l}\text { Rotation about X-Axis (Rocking) } \\
\text { WTx } 1\end{array}$} & \multirow{2}{*}{$\begin{array}{l}\text { Whether all Constraints } \\
\text { Satisfied...? }\end{array}$} & \multirow{2}{*}{$\begin{array}{l}\text { Concrete Volume of } \\
\text { Possible Solution }\end{array}$} & \multirow{2}{*}{$\begin{array}{l}\text { Least of all Possible } \\
\text { Solution }\end{array}$} \\
\hline & & & & \\
\hline 21 & 6.95 & TRUE & 368.38 & \\
\hline 22 & 7.59 & FALSE & - & \\
\hline 23 & 6.65 & TRUE & 400.16 & \\
\hline 24 & 7.41 & FALSE & - & \\
\hline 25 & 5.05 & TRUE & 543.73 & \\
\hline 26 & 5.26 & TRUE & 518.13 & \\
\hline 27 & 7.14 & FALSE & - & \\
\hline 28 & 7.43 & FALSE & - & \\
\hline 29 & 7.23 & FALSE & - & \\
\hline 30 & 6.2 & TRUE & 449.14 & \\
\hline 31 & 7.72 & FALSE & - & \\
\hline 32 & 7.5 & FALSE & - & \\
\hline 33 & 7.33 & FALSE & - & \\
\hline 34 & 7.4 & FALSE & - & \\
\hline 35 & 6.94 & FALSE & - & \\
\hline 36 & 7.58 & FALSE & - & \\
\hline 37 & 8.01 & FALSE & - & \\
\hline 38 & 6.43 & TRUE & 368.38 & \\
\hline 39 & 6.52 & TRUE & 374.17 & \\
\hline 40 & 7.64 & TRUE & 326.10 & \\
\hline 41 & 6.07 & TRUE & 433.52 & \\
\hline 42 & 7.04 & FALSE & - & \\
\hline 43 & 7.46 & FALSE & - & \\
\hline 44 & 8.17 & FALSE & - & \\
\hline 45 & 6.71 & TRUE & 360.08 & \\
\hline 46 & 7.24 & TRUE & 326.79 & \\
\hline 47 & 6.52 & TRUE & 373.32 & \\
\hline 48 & 5.09 & TRUE & 539.27 & \\
\hline 49 & 6.72 & TRUE & 401.49 & \\
\hline 50 & 7.49 & FALSE & - & \\
\hline 51 & 7.37 & FALSE & - & \\
\hline 52 & 5.46 & TRUE & 483.72 & \\
\hline 53 & 6.07 & TRUE & 434.35 & \\
\hline 54 & 6.51 & TRUE & 410.32 & \\
\hline 55 & 6.57 & TRUE & 378.81 & \\
\hline 56 & 5.61 & TRUE & 449.01 & \\
\hline 57 & 7.08 & FALSE & - & \\
\hline 58 & 7.31 & TRUE & 295.20 & \\
\hline 59 & 5.62 & TRUE & 482.24 & \\
\hline 60 & 6.93 & TRUE & 343.05 & \\
\hline 61 & 5.51 & TRUE & 468.99 & \\
\hline 62 & 6.07 & TRUE & 398.65 & \\
\hline 63 & 6.35 & TRUE & 407.05 & \\
\hline 64 & 6.43 & TRUE & 426.51 & \\
\hline 65 & 5 & TRUE & 519.38 & \\
\hline 66 & 6.8 & FALSE & - & \\
\hline 67 & 8.5 & FALSE & - & \\
\hline 68 & 6.74 & FALSE & - & \\
\hline 69 & 6.62 & TRUE & 368.45 & \\
\hline 70 & 6 & TRUE & 431.52 & \\
\hline 71 & 7.24 & TRUE & 335.76 & \\
\hline 72 & 6.58 & TRUE & 350.42 & \\
\hline 73 & 7.31 & FALSE & - & \\
\hline 74 & 5.94 & TRUE & 417.06 & \\
\hline 75 & 5.83 & TRUE & 420.75 & \\
\hline 76 & 5.86 & TRUE & 444.40 & \\
\hline 77 & 5.7 & TRUE & 453.56 & \\
\hline 78 & 6.07 & TRUE & 431.41 & \\
\hline 79 & 5.92 & TRUE & 441.18 & \\
\hline 80 & 5.92 & TRUE & 441.18 & \\
\hline 81 & 6.74 & TRUE & 371.93 & \\
\hline 82 & 5.15 & TRUE & 530.84 & \\
\hline 83 & 6.88 & TRUE & 352.96 & \\
\hline 84 & 7.61 & FALSE & - & \\
\hline 85 & 7.76 & FALSE & - & \\
\hline 86 & 7.58 & FALSE & - & \\
\hline
\end{tabular}




\begin{tabular}{|c|c|c|c|c|}
\hline Population Number & $\begin{array}{l}\text { Rotation about X-Axis (Rocking) } \\
\text { WTx_1 }\end{array}$ & $\begin{array}{l}\text { Whether all Constraints } \\
\text { Satisfied...? }\end{array}$ & $\begin{array}{l}\text { Concrete Volume of } \\
\text { Possible Solution }\end{array}$ & $\begin{array}{l}\text { Least of all Possible } \\
\text { Solution }\end{array}$ \\
\hline 87 & 5.82 & TRUE & 452.05 & \\
\hline 88 & 6.87 & TRUE & 358.87 & \\
\hline 89 & 7.71 & FALSE & - & \\
\hline 90 & 5.9 & TRUE & 474.08 & \\
\hline 91 & 5.25 & TRUE & 511.56 & \\
\hline 92 & 5.89 & TRUE & 429.76 & \\
\hline 93 & 7.24 & TRUE & 331.72 & \\
\hline 94 & 7.57 & FALSE & - & \\
\hline 95 & 5.33 & TRUE & 477.80 & \\
\hline 96 & 7.22 & FALSE & - & \\
\hline 97 & 6.92 & FALSE & - & \\
\hline 98 & 6.07 & TRUE & 426.68 & \\
\hline 99 & 6.11 & TRUE & 425.36 & \\
\hline 100 & 5.41 & TRUE & 522.06 & \\
\hline
\end{tabular}

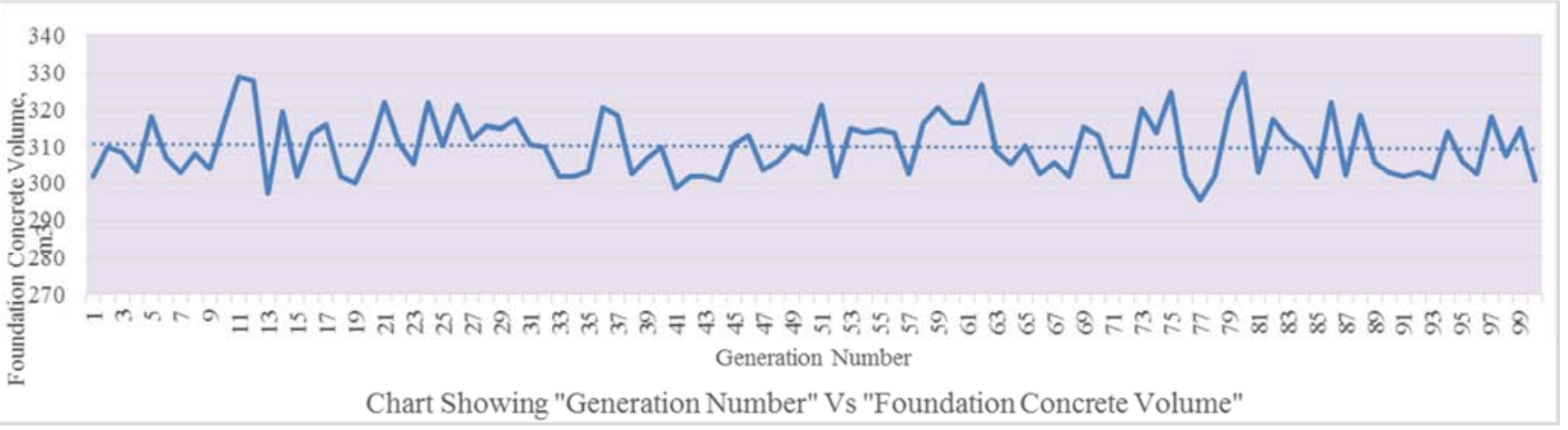

Figure 15. Generation number versus least concrete volume of respective generation.

The least concrete volume of the populations that satisfies all the constraints is considered for the above graph. Concrete volume of the populations that violate constraints are ignored.

\subsection{Verification of Optimum Solution Using ANSYS FEM Model}

\subsubsection{Ansys Model Sketches}

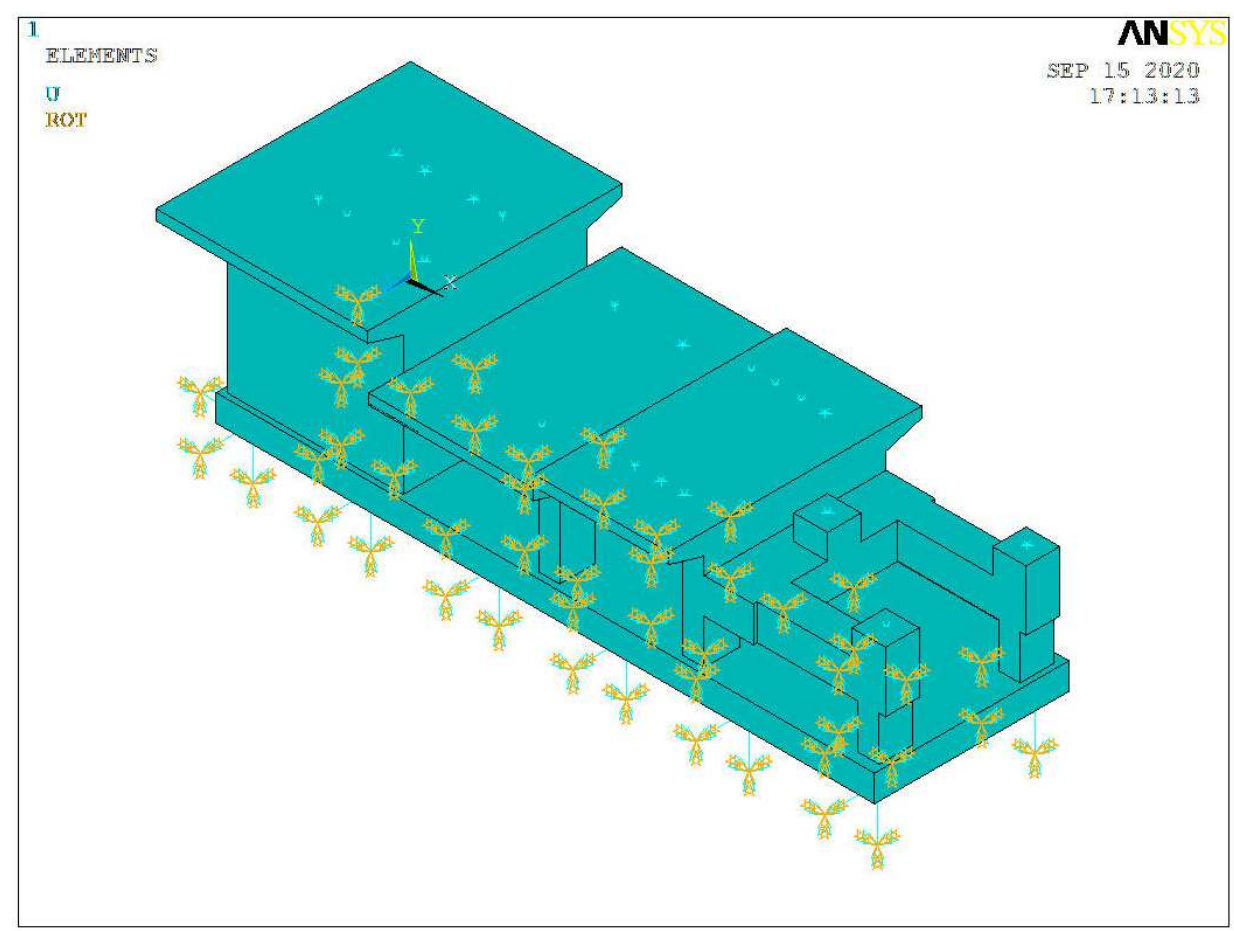

Figure 16. Ansys - Solid Model. 


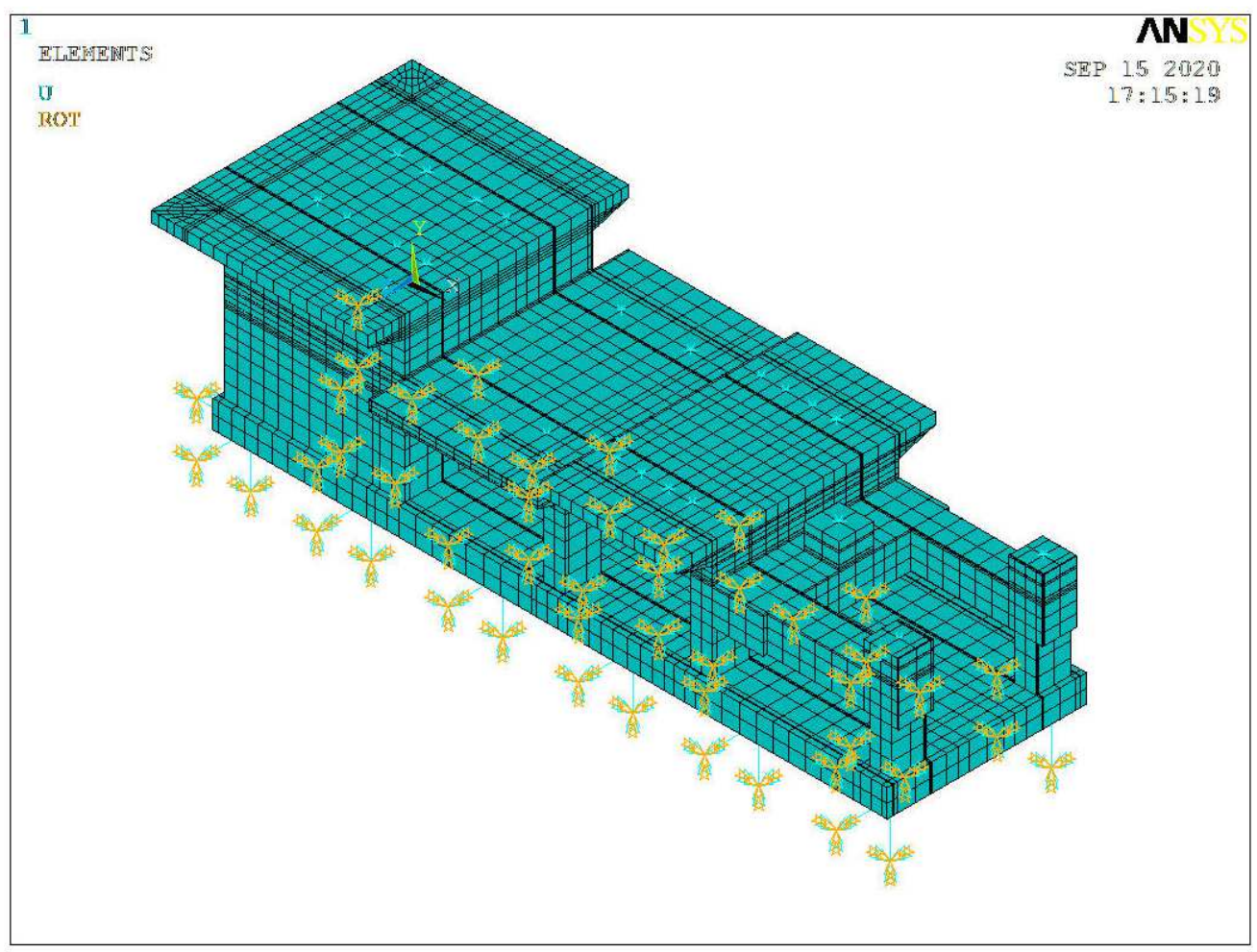

Figure 17. Ansys - Solid Model - Element Mesh.

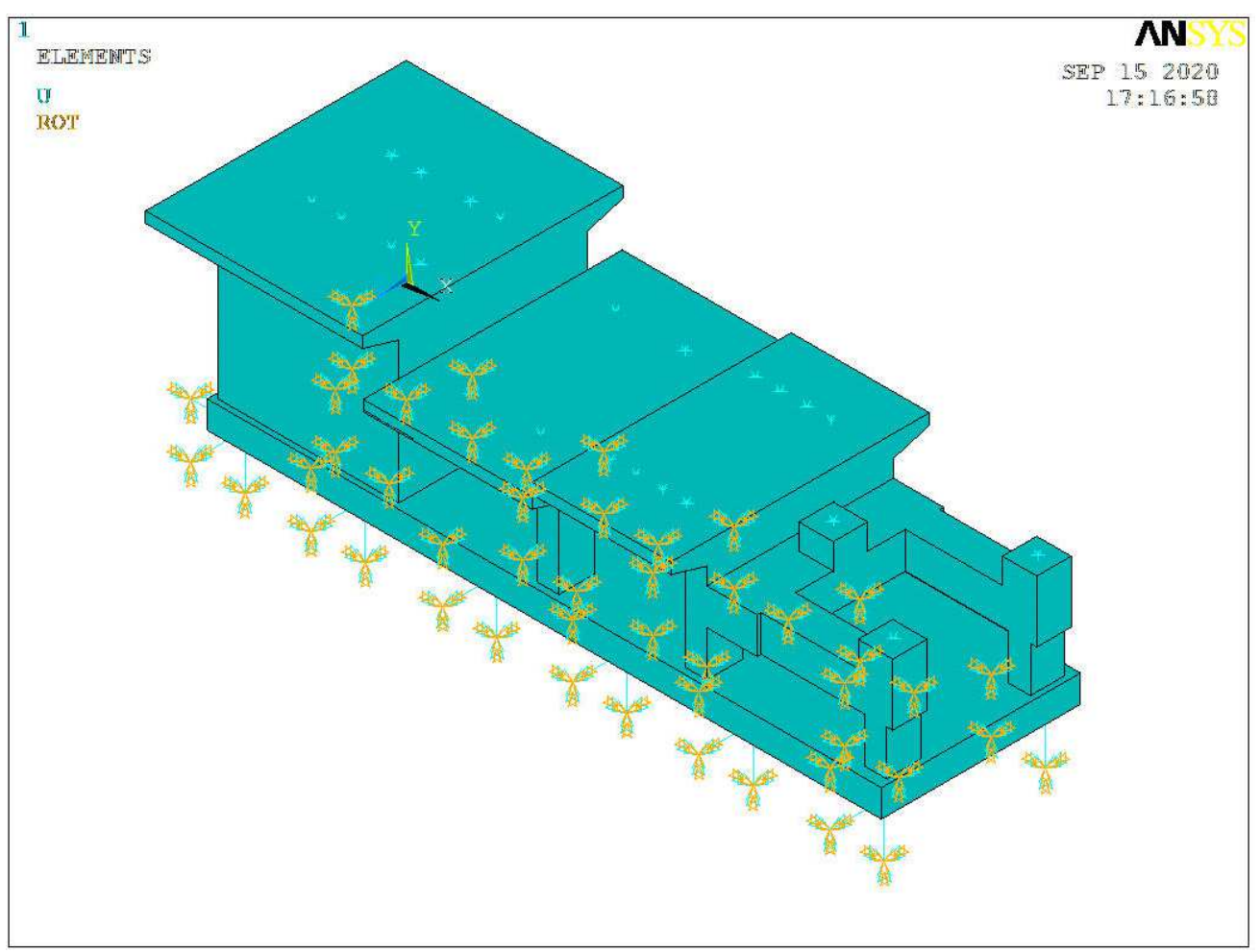

Figure 18. Ansys - Solid Model-Applied Boundary Conditions.

From the FEM analysis following results obtained. Foundation Frequency for Upper "E" value:

X-direction $=9.12 \mathrm{~Hz}$ : Mode no. 2

Z-direction $=7.15 \mathrm{~Hz}$ : Mode no. 1

Y-direction $=18.05 \mathrm{~Hz}$ : Mode no. 4

The equipment operating $=745 / 60=12.41 \mathrm{~Hz}$
The foundation frequencies are away from the equipment frequency,

$9.933 \mathrm{~Hz}(0.8 * 12.41)$ To $14.900 \mathrm{~Hz}(1.2 * 12.41)$

Also, $21.1 \mathrm{~Hz}(0.85 * 2 * 12.41)$ To $28.56 \mathrm{~Hz}(1.15 * 2 * 12.41)$

As per IS: 2974 Part-4 Criteria [13]. 
Table 6. Results Comparison.

\begin{tabular}{lllllll}
\hline Results Comparison & $\begin{array}{l}\text { Vertical direction } \\
\text { (Y-Dir) }\end{array}$ & $\begin{array}{l}\text { Rotation about } \\
\text { Y-Axis (Yawing) }\end{array}$ & $\begin{array}{l}\text { Along rotor } \\
\text { direction (X-Dir) }\end{array}$ & $\begin{array}{l}\text { Rotation about } \\
\text { Z-Axis (Pitching) }\end{array}$ & $\begin{array}{l}\text { Across rotor } \\
\text { direction (Z-Dir) }\end{array}$ & $\begin{array}{l}\text { Rotation about } \\
\text { X-Axis (Rocking) }\end{array}$ \\
\hline $\begin{array}{l}\text { Ansys Model } \\
\text { Genetic Algorithm / }\end{array}$ & 18.055 & 10.69 & 9.12 & 18.05 & 7.12 & 7.12 \\
Barkan's Method & 19.33 & 9.91 & 9.38 & 15.07 & 9.38 & 7.31 \\
\hline
\end{tabular}

From the above table, it can be seen that, Ansys FEM results are in agreement with Barkan's method results with acceptable deviations. Hence the solution obtained using Genetic Algorithm is in order and acceptable.

\subsubsection{Displacement Amplitudes for Operating Frequencies}

Table 7. Displacement Amplitudes.

\begin{tabular}{|c|c|c|c|c|c|}
\hline \multicolumn{6}{|c|}{ Upper Young's Modulus 'E' } \\
\hline \multirow{2}{*}{ Node Zone } & \multirow{2}{*}{ Node no. } & \multirow{2}{*}{ Range of Frequency } & \multicolumn{3}{|c|}{ Max displacement Amplitude in meter } \\
\hline & & & $\mathbf{U x}$ & $\mathbf{U y}$ & $\mathbf{U z}$ \\
\hline \multirow{12}{*}{ FAN } & 70409 & $11-14 \mathrm{~Hz}$ & $2.37 \mathrm{E}-07$ & $4.82 \mathrm{E}-07$ & $5.82 \mathrm{E}-07$ \\
\hline & 72976 & $11-14 \mathrm{~Hz}$ & $2.42 \mathrm{E}-07$ & 4.64E-07 & $8.50 \mathrm{E}-07$ \\
\hline & 76120 & $11-14 \mathrm{~Hz}$ & $2.25 \mathrm{E}-07$ & $4.36 \mathrm{E}-07$ & $1.17 \mathrm{E}-06$ \\
\hline & 76116 & $11-14 \mathrm{~Hz}$ & $2.28 \mathrm{E}-07$ & 4.27E-07 & $1.26 \mathrm{E}-06$ \\
\hline & 80911 & $11-14 \mathrm{~Hz}$ & $2.32 \mathrm{E}-07$ & 4.07E-07 & $1.35 \mathrm{E}-06$ \\
\hline & 74812 & $11-14 \mathrm{~Hz}$ & $2.36 \mathrm{E}-07$ & $4.01 \mathrm{E}-07$ & $1.43 \mathrm{E}-06$ \\
\hline & 73483 & $11-14 \mathrm{~Hz}$ & $2.45 \mathrm{E}-07$ & $4.83 \mathrm{E}-07$ & $5.82 \mathrm{E}-07$ \\
\hline & 73466 & $11-14 \mathrm{~Hz}$ & $2.50 \mathrm{E}-07$ & $4.66 \mathrm{E}-07$ & $8.50 \mathrm{E}-07$ \\
\hline & 76653 & $11-14 \mathrm{~Hz}$ & $2.32 \mathrm{E}-07$ & 4.39E-07 & $1.17 \mathrm{E}-06$ \\
\hline & 76642 & $11-14 \mathrm{~Hz}$ & $2.35 \mathrm{E}-07$ & $4.30 \mathrm{E}-07$ & $1.26 \mathrm{E}-06$ \\
\hline & 80997 & $11-14 \mathrm{~Hz}$ & 4.05E-07 & $4.11 \mathrm{E}-07$ & $1.35 \mathrm{E}-06$ \\
\hline & 75111 & $11-14 \mathrm{~Hz}$ & 2.43E-07 & 4.09E-07 & $1.43 \mathrm{E}-06$ \\
\hline \multirow{8}{*}{ MOTOR } & 26367 & $11-14 \mathrm{~Hz}$ & $1.35 \mathrm{E}-07$ & $4.08 \mathrm{E}-07$ & 4.62E-07 \\
\hline & 44199 & $11-14 \mathrm{~Hz}$ & $1.37 \mathrm{E}-07$ & 4.07E-07 & 4.62E-07 \\
\hline & 51145 & $11-14 \mathrm{~Hz}$ & $1.34 \mathrm{E}-07$ & $4.12 \mathrm{E}-07$ & 4.77E-07 \\
\hline & 53484 & $11-14 \mathrm{~Hz}$ & $1.37 \mathrm{E}-07$ & $4.10 \mathrm{E}-07$ & 4.78E-07 \\
\hline & 58108 & $11-14 \mathrm{~Hz}$ & $1.34 \mathrm{E}-07$ & $4.17 \mathrm{E}-07$ & $5.03 \mathrm{E}-07$ \\
\hline & 58120 & $11-14 \mathrm{~Hz}$ & $1.36 \mathrm{E}-07$ & $4.16 \mathrm{E}-07$ & $5.03 \mathrm{E}-07$ \\
\hline & 45387 & $11-14 \mathrm{~Hz}$ & $1.34 \mathrm{E}-07$ & $4.22 \mathrm{E}-07$ & $5.29 \mathrm{E}-07$ \\
\hline & 46048 & $11-14 \mathrm{~Hz}$ & $1.36 \mathrm{E}-07$ & $4.21 \mathrm{E}-07$ & $5.29 \mathrm{E}-07$ \\
\hline
\end{tabular}

The allowable displacement amplitude $=200 \mu \mathrm{m}$ (Clause 5.4.1 of IS: 2974 [13].

At motor and Fan operating frequencies the amplitudes are $<200 \mu \mathrm{m}$

The limiting vibration amplitude as per equipment manufacturer and ISO 10816-3 [15] $=4.5 \mathrm{~mm} / \mathrm{sec}$

$=\operatorname{Sqrt}(2) \times 4.5 \times(1 /(2 * \operatorname{pi}() * 12.4))=0.081 \mathrm{~mm}$

$=81 \mu \mathrm{m}$

From the above, the actual amplitudes are within the limits.

\section{Conclusions}

The design variables in most of the civil engineering optimization problems are discrete. Genetic algorithms handle discrete variables efficiently. Hence Genetic algorithms are best suited for civil engineering optimization.

Literature study shows successful application of Genetic Algorithms to various design applications [7]. Identified machine foundation design is the area where there is scope for optimization and simplifying the search for practicable solution.

Scope of genetic algorithm application for fan foundation is studied in chapter-4. Unlike mill and turbo generator foundation, fan foundation frequency separation criteria found to be directly influenced by assumed member sizes, material parameters and shape of the foundation. It is found that, there is a scope for finding the best possible optimum solution under complex situations satisfying the dynamic criteria by keeping member sizes, material parameters and shape of the foundation as variables.

It is established that optimum solution obtained using GA's is having less concrete volume as against solution obtained using manual trails. Thus, application of GA's has provided an optimum solution with savings in concrete volume which is $10.60 \%$ lesser. Hence it is established that, GA's can be successfully used for optimization of fan foundations which are practicable to construct and operate in real time. The same is verified by full scale modelling in ANSYS software and proved the results are in agreement with that obtained using genetic algorithms.

\section{References}

[1] Jenkins, W. M., (1991) "Towards Structural Optimization via the Genetic Algorithms", Computers and Structures, Vol. 40, No. 5, pp 1321-1327. 
[2] Gold berg, D. E., (1989), "Genetic Algorithm in Search Optimization and Machine Learning", Addition - Wesley Publishing Company Inc., Reading, Massachusetts.

[3] Rajeev, S., Krishnamoorthy, C. S., (1992), "Discrete Optimization of Structures using Genetic Algorithms". Journal of Structural Engineering, Vol. 118, No. 5. Pp 1233-1250.

[4] Rajeev, S., Krishnamoorthy, C. S., (1992), "Genetic Algorithms Discussion by Laurence Schmid", Journal of Structural Engineering.

[5] Rajeev, S., Krishnamoorthy, C. S., (1993), "Structural Optimization using Genetic Algorithms", A paper presented at Advanced Study Institute on Computational Methods for Engineering Analysis and Design, IIT, Madras.

[6] Saxena, Ashutosh., George, Suju. M., Rambabu, P., (1993), "Effectiveness of Variations in Mutation Operator in Genetic Algorithm", Proceedings of the International Computing Congress at Hyderabad.

[7] Tanweer Alam, Shamimul Qamar, Amit Dixit, Mohamed Benaida (2020) "Genetic Algorithm: Reviews, Implementations and Applications" A Paper published in International Journal of Engineering Pedagogy (iJEP).

[8] P Srinivasulu and C V Vaidyanathan, (2018) "Hand Book of Machine Foundations" Structural Engineering Research Centre, Madras.
[9] Hongchun Liu, Chair of the ASCE Task Committee for "Turbine-Generator Foundations - State-of-Practice Review" Conference on Structures Congress, April 19-21, 2018 | Fort Worth, Texas.

[10] Reddeppa Nulu, Jayarami Reddy Bommireddy, Hanchate Sudarsana Rao. (2020) "Foundation for Primary Air Fan of speed $1490 \mathrm{rpm}$ - Study of dynamic behavior" SCIREA Journal of Civil Engineering and Building Construction.

[11] Reddeppa Nulu, Jayarami Reddy Bommireddy, Hanchate Sudarsana Rao. (2020) "ID Fan Foundation: Study of Dynamic Behavior" A paper presented at Springer Journal of Inst. Eng. India Ser. A.

[12] Anonymous, IS: 2974 (Part-3) - 1992, “Design and Construction of Machine Foundations - Foundations For Rotary Type Machines (Medium and High Frequency)", Bureau of Indian Standards.

[13] Anonymous, IS: 2974 (Part-4) - 2000, "Design and Construction of Machine Foundations - Foundations For Rotary Type Machines (Low Frequency)", Bureau of Indian Standards.

[14] Suresh Arya, Michel O' Neil, Gorge Pincus (1981) "Design of structures and Foundation for Vibrating Machines".

[15] Anonymous, ISO 10816-3 "Mechanical vibration Evaluation of machine vibration by measurements on nonrotating parts - Part-3". 